Cite this: Dalton Trans., 2014, 43, 4451

Received 23rd September 2013, Accepted 26th November 2013

DOI: $10.1039 / c 3 d t 52637 b$

www.rsc.org/dalton

\section{Synthesis, characterization and reactivity of an imidazolin-2-iminato aluminium dihydride $\uparrow$}

\author{
Daniel Franz, Elisabeth Irran and Shigeyoshi Inoue*
}

\section{Introduction}

\section{Aluminium hydrides - versatile reagents with rich chemistry}

For many years, chemical synthesis has been gaining immense benefit from the distinct reactivity of the aluminium-hydrogen bond. The strong need for highly selective transformations, increased focus on safety considerations, and efficiency in handling and storage are only some reasons why we find the chemically rogue parent aluminium hydride tamed into more suitable forms today. A variety of hydridoalanes has been tailored and very often reactivity adjustment is realized by steric congestion at the aluminium centre and by attaching strongly electron-donating substituents to the aluminium atom. Furthermore, hydridoalanes are used in a diverse range of applications. For instance, the hydroalumination of carbonyl ${ }^{1,2}$ and alkyne $^{3-7}$ functionalities is a common application for this class of compounds in organic synthesis. Though the intermediate aluminium species in these reactions are often elusive, the use of aluminium hydrides such as $\mathbf{I}^{8}$ (Fig. 1) that bear highly sophisticated ligands grants access to all types of isolatable and well-defined model complexes. Compound I can be categorized as an aluminium dihydride and is related to the parent aluminium trihydride by replacement of one hydride for an anionic ligand. Thus, an ancillary ligand may

Institut für Chemie, Technische Universität Berlin, Straße des 17. Juni 135, Sekr. C2, 10623 Berlin, Germany. E-mail: shigeyoshi.inoue@tu-berlin.de

$\dagger$ Electronic supplementary information (ESI) available: Procedures for the conversion of 2 with $\mathrm{BX}_{3}(\mathrm{X}=\mathrm{Cl}, \mathrm{Br})$ and respective NMR spectra, NMR spectra of $\mathbf{6}$, synthesis of $\mathbf{8}$, details of quantum mechanical calculations. CCDC 962234-962240 for 2-8. For ESI and crystallographic data in CIF or other electronic format see DOI: 10.1039/c3dt52637b<smiles></smiles><smiles></smiles>

I II

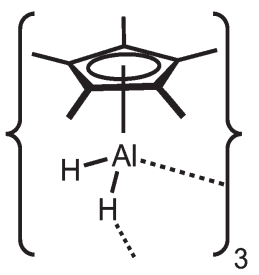

III

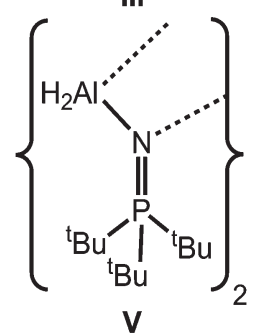

V

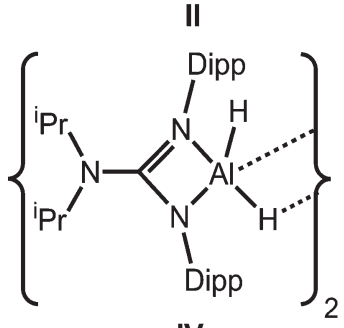

IV<smiles>CCCN1NN(C(C)C)c2ccccc21</smiles>

Fig. 1 Selected aluminium dihydride compounds. The pincer complex I, the $\beta$-diketiminato complex II, and the trimeric cyclopentadienide III. The guanidinate IV, the phosphinimide $\mathbf{V}$, as well as the troponimide VI (Dipp = 2,6-diisopropylphenyl).

be introduced, and yet, two reactive functional groups at the metal centre are preserved for the purpose of follow-up chemistry. The $\beta$-diketimino group, in particular, has been a key ligand to a rich chemistry of respective aluminium dihydrides. $^{9-12}$ A prominent example is II (Fig. 1), which can 
be used for the activation of non-polar element-element bonds as demonstrated by its conversion with elemental sulphur or selenium. ${ }^{9,10}$ In a different field of applied science one finds chemical vapour deposition technology exploiting the thermodynamic properties of molecular aluminium hydrides for the purpose of creating composite materials. $^{1,13-15}$

Aluminium hydrides are considered as fuel storagematerials with reasonable prospects in a hydrogen-based alternate energy-supply concept. ${ }^{16,17}$ Moreover, the application of aluminium hydrides in the synthesis of low-valent aluminium compounds has been reported and $\mathbf{I I I}^{18}$ (Fig. 1) is a very recent example among others ${ }^{19}$ of an intriguing nature. Recently, scarce $\sigma$-alane complexes of transition metals (e.g. Cr, Mo, W, Mn) implementing ligands such as $\mathbf{I V}^{19}$ (Fig. 1) have been described..$^{20,21}$ The particular character of the aluminium hydride moiety in transition-metal complexes will most certainly be subject to ongoing profound study.

For advocating the diversity of ligand systems employed in the field we would select the phosphinimide $\mathbf{V}^{22}$ (Fig. 1) as a rare example for the application of this particular electron donating group in aluminium hydride chemistry. A number of non-hydride aluminium complexes with this ligand system have been reported, as well. ${ }^{22-24}$ Furthermore, a troponiminato ligand can be used to stabilize the monomeric dihydride species in VI (Fig. 1). ${ }^{25}$

\section{The imidazolin-2-iminato ligand - a potent electron donor}

The development of a new ligand to control the properties and the reactivity of an aluminium hydride is one indispensable part of this chemistry and hence an important research aim. An imidazolin-2-imino group as an ancillary ligand can be considered a suitable bulky and electron donating group for a novel aluminium dihydride. The imidazolin-2-iminato ligands act as a $2 \sigma$ - and either a $2 \pi$ - or a $4 \pi$-electron donor and, in consequence, some multiple-bond character in the interaction between the nitrogen atom and the metal centre may result. ${ }^{26-31}$ Fine-tuning of this ligand system with respect to its steric and electronic properties can be conveniently accomplished by altering the substituents to the ring. ${ }^{28,30}$ Pioneering work related to main group metal complexes of the imidazolin-2-iminato ligand was done by Kuhn and coworkers (VII, Fig. 2). ${ }^{32,33}$ Contemporary research on transition metal- and rare earth metal complexes of this imino group is mainly carried out by Tamm and coworkers. ${ }^{28-30,34}$ For example, striking activity as a catalyst for propylene polymerization is ascribed to the titanium complex VIII ${ }^{30}$ (Fig. 2) which is representative for the field. Most remarkably, the phosphinonitrene IX (Fig. 2) was described by Bertrand and coworkers, thus demonstrating the high potential of this ligand system in main group element chemistry. ${ }^{35-37}$ Recently, we have demonstrated the application of the bis(2,6-diisopropylphenyl)imidazolin-2-imino group in the synthesis of the unprecedented silylene $\mathbf{X}$ (Fig. 2). ${ }^{31}$

Herein we report the synthesis and characterization of the hitherto unknown bis(2,6-diisopropylphenyl)imidazolin-2-

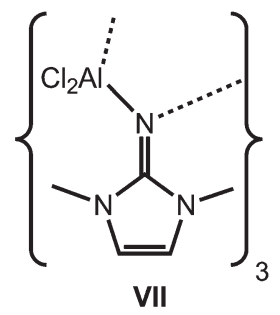<smiles>CC(C)Cn1ccn(C(C)(C)C)c1=N[I](Cl)(Cl)N=c1n(CC(C)(C)C)ccn1C(C)(C)C</smiles>

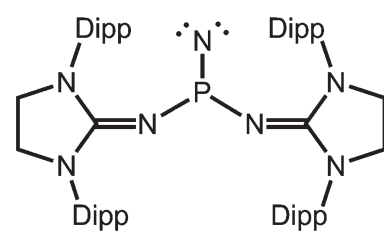

IX

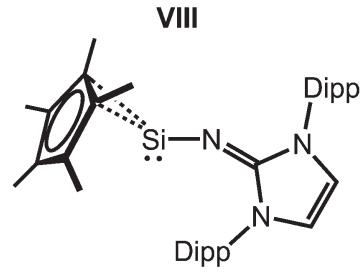

$\mathbf{X}$
Fig. 2 Imidazolin-2-imino compounds with main group elements (VII, IX, X) and the titanium complex VIII (Dipp = 2,6-diisopropylphenyl).

imino aluminium dihydride $\left\{\mu-\mathrm{LAlH}_{2}\right\}_{2} 2$ and its reactivity as a hydride transfer reagent.

\section{Results and discussion}

\section{Introduction of the bulky imidazolin-2-imino group to the} aluminium centre

In order to introduce the bis(2,6-diisopropylphenyl)imidazolin-2-iminato ligand $\left(\mathrm{L}^{-}\right)$to a hydridoalane moiety we found it reasonable to adopt a procedure ${ }^{22}$ reported by Stephan and coworkers for the synthesis of a related phosphinimide. The stoichiometric reaction of $\mathrm{LH}(\mathbf{1})^{38}$ with $\mathrm{Me}_{3} \mathrm{~N} \cdot \mathrm{AlH}_{3}$ in toluene affords the dimeric aluminium dihydride $\left\{\mu-\mathrm{LAlH}_{2}\right\}_{2}$ (2) in sufficient yield (66\%) as confirmed by multinuclear NMR spectroscopy, high resolution mass spectrometry, single-crystal $\mathrm{X}$-ray diffraction data, and elemental analysis (Scheme 1).

In the infrared spectrum the bands at $1830 \mathrm{~cm}^{-1}$ and $1798 \mathrm{~cm}^{-1}$ are assigned to the $\mathrm{Al}-\mathrm{H}$ bonds in 2 , which is in accordance with the IR absorptions reported for the related

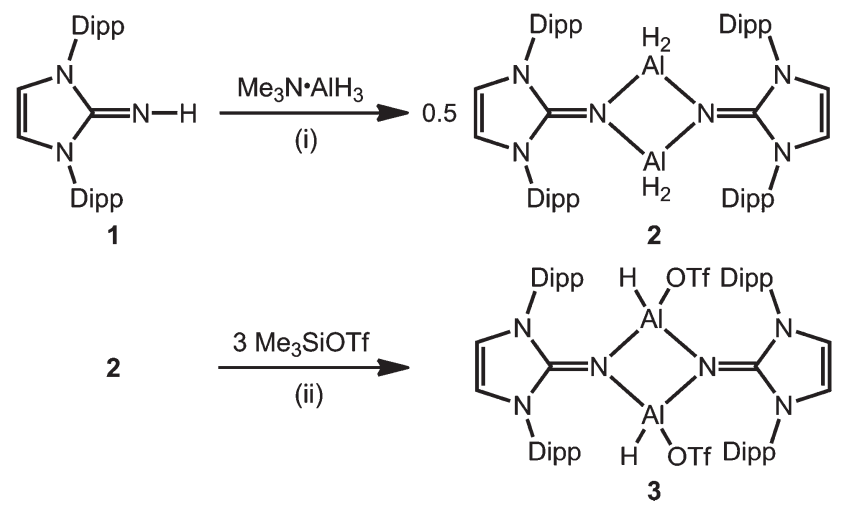

Scheme 1 Formation of the imidazolin-2-imino aluminium hydride 2 via conversion of the imine 1 and synthesis of its triflate derivative 3 . (i) Toluene, (1) $-78^{\circ} \mathrm{C}, 2 \mathrm{~h}$, (2) rt, $24 \mathrm{~h}$. (ii) Toluene, (1) $0^{\circ} \mathrm{C}, 30 \mathrm{~min}$, (2) rt, 24 h. Dipp $=2,6$-diisopropylphenyl, $\mathrm{Tf}=\mathrm{SO}_{2} \mathrm{CF}_{3}$. 
aluminium dihydride $\mathbf{I I} .^{10}$ The resonance pattern observed for the imidazolin-2-iminato moiety in the ${ }^{1} \mathrm{H}$ and ${ }^{13} \mathrm{C}\left\{{ }^{1} \mathrm{H}\right\}$ NMR spectra of 2 resembles the one in related silicon complexes such as $\operatorname{LSi}\left(\mathrm{C}_{5} \mathrm{Me}_{5}\right) \mathrm{Br}_{2} \cdot{ }^{31}$ In the proton NMR spectrum $\left(\mathrm{C}_{6} \mathrm{D}_{6}\right)$, a broad resonance at 2.60 ppm with $4 \mathrm{H}$ intensity is observed that can be assigned to the hydrogen atoms of the $\mathrm{AlH}_{2}$ moieties and is more shielded than those observed for amidino-, $\beta$-diketimino-, or 1-azaallyl aluminium dihydrides $(4.60 \mathrm{ppm}-$ $4.87 \mathrm{ppm})^{39-41}$ and the starting material $\mathrm{Me}_{3} \mathrm{~N} \cdot \mathrm{AlH}_{3}$ $(4.08 \mathrm{ppm})$, as well as $\left[\mathrm{Me}_{2} \mathrm{NAlH}_{2}\right]_{3}(3.8 \mathrm{ppm})^{42}$ but is shifted more downfield than that of aluminium dihydride VI (1.08 ppm, Fig. 1). ${ }^{25}$ After heating a solution of 2 in toluene to reflux temperature over a period of $12 \mathrm{~h}$ the NMR spectroscopic control did not reveal any signs of decomposition which accounts for the thermal stability of this aluminium dihydride. Compound 2 crystallizes from hexane-toluene in the monoclinic space group $P 2_{1} / c$ and the unit cell contains two crystallographically independent centrosymmetric molecules. In one of these molecules, the two equivalent aluminium atoms are disordered over two sites. Since the structural parameters of the two molecules are almost identical, we discuss only the one for which no disordered metal atom is observed. The single-crystal X-ray data of 2 reveals the four-membered $\mathrm{Al}_{2} \mathrm{~N}_{2}$ ring as the prominent structural motif of the dimer (Fig. 3). The Al-N bond distances of 1.912(1) $\AA$ and 1.915(1) $\AA$ in 2 are slightly longer than those in compound V $(\mathrm{Al}-\mathrm{N}=1.887(3)-1.905(3) \AA) .{ }^{22}$ The $\mathrm{N}(1)-\mathrm{Al}(1)-\mathrm{N}(1 \mathrm{~A})$ and

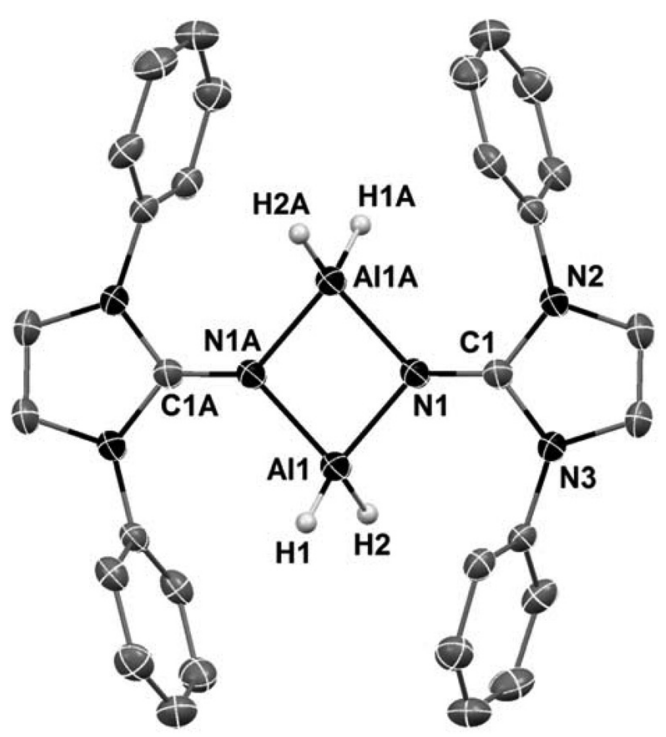

Fig. 3 Molecular structure of 2 in the solid state. The unit cell contains two independent molecules and only one is shown; hydrogen atoms (except on aluminium) and isopropyl groups have been omitted for clarity; displacement ellipsoids are drawn at the $50 \%$ probability level. Selected bond lengths $(\AA)$, atom $\cdots$ atom distance $(\AA)$, bond angles $\left(^{\circ}\right)$, and dihedral angle $\left(^{\circ}\right)$ : $\mathrm{Al}(1)-\mathrm{N}(1)$ 1.915(1), $\mathrm{Al}(1)-\mathrm{N}(1 \mathrm{~A})$ 1.912(1), $\mathrm{Al}(1)-\mathrm{H}(1)$ 1.48(2), $\mathrm{Al}(1)-\mathrm{H}(2)$ 1.55(2), $\mathrm{N}(1)-\mathrm{C}(1) \quad 1.289(2), \quad \mathrm{N}(2)-\mathrm{C}(1)$ 1.389(2), $\mathrm{Al}(1) \cdots \mathrm{Al}(1 \mathrm{~A}) \quad 2.795(1) ; \mathrm{H}(1)-\mathrm{Al}(1)-\mathrm{H}(2)$ 118(1), N(1)-Al(1)-N(1A) 86.2(1), $\mathrm{Al}(1)-\mathrm{N}(1)-\mathrm{Al}(1 \mathrm{~A}) \quad 93.8(1), \quad \mathrm{Al}(1)-\mathrm{N}(1)-\mathrm{C}(1) \quad 131.7(1), \quad \mathrm{Al}(1 \mathrm{~A})-\mathrm{N}(1)-\mathrm{C}(1)$ 134.0(1); $\mathrm{N}(1 \mathrm{~A})-\mathrm{Al}(1)-\mathrm{N}(1)-\mathrm{Al}(1 \mathrm{~A}) 0.0$. Symmetry transformation used to generate equivalent atoms: $A:-x+1,-y+2,-z+1$.
$\mathrm{Al}(1)-\mathrm{N}(1)-\mathrm{Al}(1 \mathrm{~A})$ angles in 2 are $86.2(1)^{\circ}$ and $93.8(1)^{\circ}$, respectively. The dihedral angle $\mathrm{N}(1 \mathrm{~A})-\mathrm{Al}(1)-\mathrm{N}(1)-\mathrm{Al}(1 \mathrm{~A})$ of $0.0^{\circ}$ confirms that these four atoms are all located in one plane. The $\mathrm{Al}(1) \cdots \mathrm{Al}(1 \mathrm{~A})$ distance in 2 amounts to $2.795(1) \AA$, which is significantly longer than the metal-metal bond lengths in characteristic donor-stabilized dialanes with four-coordinated aluminium centres. ${ }^{19,43}$ The $\mathrm{N}(1)-\mathrm{C}(1)$ bond length of $1.289(2)$ $\AA$ in 2 only differs slightly from the analogous values in silicon compounds stabilized by imidazolin-2-iminato ligands. ${ }^{31,38}$ Furthermore, it is similar to that of the guanidinate $\left\{\mu-\left(\mathrm{Me}_{2} \mathrm{~N}\right)_{2} \mathrm{CNAl}\left(\mathrm{NMe}_{2}\right)_{2}\right\}_{2} \cdot{ }^{44}$ The 5-membered imidazoline ring plane is tilted versus the central $\mathrm{Al}_{2} \mathrm{~N}_{2}$ moiety by $9^{\circ}$. The sum of the bond angles around the nitrogen atom attached to the aluminium centre amounts to $360^{\circ}$, which confirms the trigonal-planar geometry around the nitrogen atom of the imino group.

\section{DFT calculations of related aluminium dihydrides}

For obvious reasons, the reactivity of an aluminium dihydride will largely depend on its hydride-donor strength, and one would expect that the tendency for hydride release depends on the electron density at the hydrogen atoms and the nature of the $\mathrm{Al}-\mathrm{H}$ bonds. Hence, we performed quantum-mechanical calculations on a sterically reduced model compound of 2 ( 2 ', Fig. 4) and related model compounds with a four-coordinated

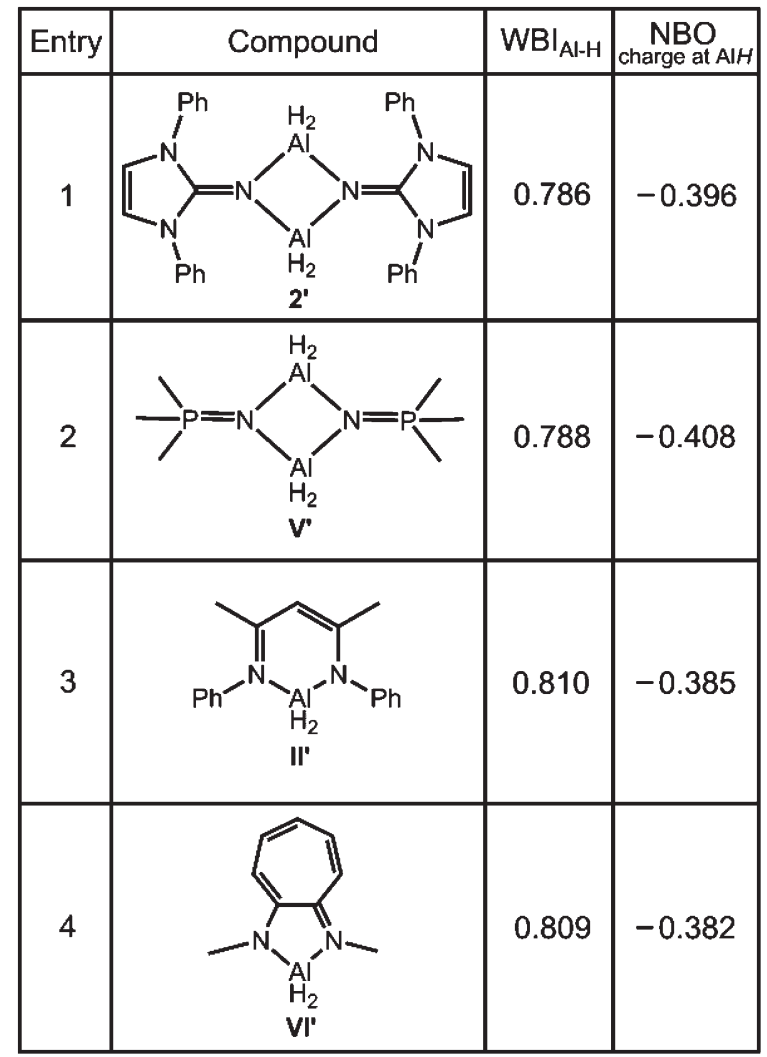

Fig. 4 Calculated Wiberg bond indices of the Al-H bonds and NBO charges at the hydride atoms for the simplified model compounds $2^{\prime}, \mathrm{II}^{\prime}$, $\mathrm{VI}^{\prime}$, and $\mathrm{V}^{\prime}$. 
aluminium centre of $\mathbf{I I},{ }^{10} \mathbf{V},{ }^{22}$ and $\mathbf{V I}^{25}$ (i.e. $\mathbf{I I}^{\prime}, \mathbf{V}^{\prime}$, and $\mathbf{V I}^{\prime}$; Fig. 4) at the B3LYP/6-31G(d) level of theory ( $c f$. the ESI† for computational details). The optimized structures of the model compounds matched the experimental data. According to the NBO charges, each $\mathrm{H}$ atom at the aluminium centre in $2^{\prime}$ bears a negative net charge $(-0.396)$, which is more negative than those in $\mathbf{I I}^{\prime}(-0.385)$ and $\mathbf{V I}^{\prime}(-0.382)$, but more positive than that in $\mathbf{V}^{\prime}(-0.408)$. Interestingly, the calculated WBI values of the $\mathrm{Al}-\mathrm{H}$ bonds in $\mathbf{2}^{\prime}(0.786)$ are smaller than those in $\mathbf{I I}^{\prime}$ (0.810), $\mathbf{V}^{\prime}$ (0.788), and VI' (0.809) and the lower bond order implies a higher polarization of the $\mathrm{Al}-\mathrm{H}$ group. Consequently, reactivity enhancement towards highly polarized electrophiles may coincide. These results suggest that 2 is a strong hydride donor reagent.

\section{Hydride abstraction from $\left\{\boldsymbol{\mu}-\mathrm{LAlH}_{2}\right\}_{2}(2)$}

Due to the strong electron-donor character of the iminato ligand $\mathrm{L}^{-}$and its steric congestion we had reason to expect a structural motif with discrete $\mathrm{LAlH}_{2}$ moieties in the solid state instead of the formation of dimers as evidenced by the single crystal X-ray data of $\left\{\mu \text { - } \mathrm{LAlH}_{2}\right\}_{2}(2)$ and its high resolution mass spectrum (vide supra). Stimulated by a report of Stephan and coworkers about the reaction of $\mathbf{V}$ with trimethylsilyltriflate to $\left\{\mu-\left({ }^{\mathrm{t}} \mathrm{Bu}\right)_{3} \mathrm{PNAl}(\mathrm{H}) \mathrm{OTf}\right\}_{2},{ }^{22}$ we treated 2 with three equivalents of $\mathrm{Me}_{3} \mathrm{SiOTf}\left(\mathrm{Tf}=\mathrm{SO}_{2} \mathrm{CF}_{3}\right.$ ), which resulted in replacement of one hydride substituent per aluminium centre by a triflate group (Scheme 1). Compound $3\{\mu-\mathrm{LAl}(\mathrm{H}) \mathrm{OTf}\}_{2}$ was obtained in analytically pure form after repeated recrystallization from THFhexane. It was characterized by multinuclear NMR spectroscopy, high resolution mass spectrometry, single-crystal $\mathrm{X}$-ray study, and elemental analysis. Though the symmetry at the aluminium centre in $\mathbf{3}$ is lowered in comparison to its precursor, a resonance pattern similar to that of 2 is observed in the ${ }^{1} \mathrm{H}$ and ${ }^{13} \mathrm{C}\left\{{ }^{1} \mathrm{H}\right\}$ NMR spectra of 3 in $\mathrm{CD}_{3} \mathrm{CN}$. Similar to 2 , the molecular structure of 3 in the solid state reveals a dimer with a central $\mathrm{Al}_{2} \mathrm{~N}_{2}$ core (Fig. 5). Two triflate groups are found assuming positions on the same side of the $\mathrm{Al}_{2} \mathrm{~N}_{2}$ ring, thus their configuration is pseudo-cis which is reminiscent of the phosphinimide congener $\left\{\mu-\left({ }^{\mathrm{t}} \mathrm{Bu}\right)_{3} \mathrm{PNAl}(\mathrm{H}) \mathrm{OTf}\right\}_{2} \cdot{ }^{22}$ As marked by the dihedral angle $\mathrm{N}(4)-\mathrm{Al}(1)-\mathrm{Al}(2)-\mathrm{N}(1)=169.6(2)^{\circ}$ the reduced symmetry around the $\mathrm{Al}_{2} \mathrm{~N}_{2}$ ring inflicts slight deviation from its square-planar geometry that is observed for 2 (Fig. 3) in very high approximation. The Al-N bond lengths of 3 are found in a range from 1.849(3) A to 1.872(3) $\AA$ and are notably shorter than those in 2 . This indicates that the triflate substituents in 3 render the aluminium centres more electrophilic, thus strengthening the interaction with the nitrogen atoms of the adjacent ligands.

While the replacement of one hydride at the aluminium atom for $\mathrm{OTf}^{-}$proceeded readily, we were not able to isolate a related species with a ditriflated metal centre even when treating $\{\mu \text {-LAlH }\}_{2}$ (2) with a large excess of $\mathrm{Me}_{3}$ SiOTf at an elevated temperature.

As an alternative group of electrophiles that might elucidate the hydride-donating properties of 2 , we conceived boroncentred Lewis acids. The turn from silicon to boron is

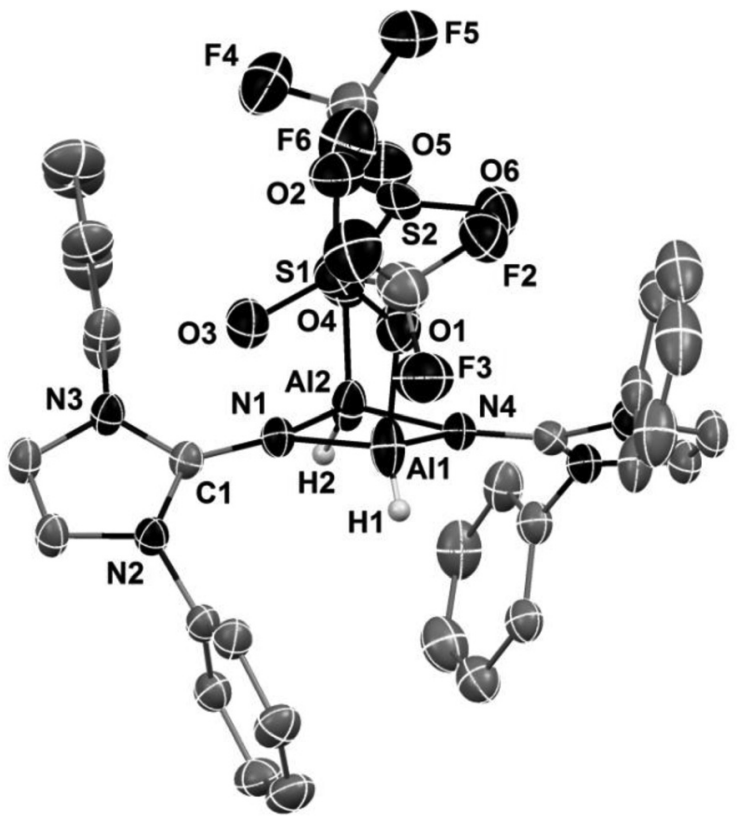

Fig. 5 Molecular structure of $3(\mathrm{THF})_{3}$ in the solid state. Hydrogen atoms (except on aluminium), isopropyl groups, and THF molecules have been omitted for clarity; only the higher occupied site is shown for atoms disordered over two sites; displacement ellipsoids are drawn at the $50 \%$ probability level. Selected bond lengths (Å), atom $\cdots$ atom distance $(\AA)$, bond angles $\left({ }^{\circ}\right)$, and dihedral angle $\left({ }^{\circ}\right)$ : Al(1) $-\mathrm{N}(4) 1.849(3)$, $\mathrm{Al}(2)-\mathrm{N}(4)$ 1.872(3), N(1) $-\mathrm{C}(1)$ 1.327(5), N(2)-C(1) 1.376(5), Al(1)...Al(2) 2.666(2); $\mathrm{N}(1)-\mathrm{Al}(2)-\mathrm{N}(4) \quad 87.7(2), \mathrm{Al}(1)-\mathrm{N}(1)-\mathrm{Al}(2) \quad 91.6(2) ; \mathrm{N}(4)-\mathrm{Al}(1)-$ $\mathrm{Al}(2)-\mathrm{N}(1) 169.6(2)$.

reasonable because the diagonal relationship between these elements is one of the many verified reactivity patterns emerging from the periodic table. ${ }^{45}$ Recently, Harder and Spielmann reported the synthesis of the $\beta$-diketiminato-stabilized (Dipp)nacnacAl $\left(\mathrm{BH}_{4}\right)_{2}$ by reaction of II with $\operatorname{DippNH}_{2} \cdot \mathrm{BH}_{3} \cdot{ }^{46}$ Inspired by these findings, we set out to react 2 with four equivalents of borane dimethylsulphide complex (Scheme 2). As the outcome of the presumed hydride transfer from the aluminium centre to the boron atom $\left\{\mu-\mathrm{LAl}\left(\mathrm{BH}_{4}\right)_{2}\right\}_{2}$ (4) was formed as elucidated by multinuclear NMR spectroscopy, single-crystal X-ray structure determination, elemental analysis, as well as high resolution mass spectrometric analysis.

An early synthesis of the parent $\mathrm{Al}\left(\mathrm{BH}_{4}\right)_{3}$ goes back to Brown and coworkers. ${ }^{47}$ Aluminium borohydride is described as a hazardous material, particularly because the vapour of the liquid substance may spontaneously detonate upon contact with air and moisture. In addition, it slowly decomposes at room temperature with the release of dihydrogen. ${ }^{47}$ In recent years, $\mathrm{Al}\left(\mathrm{BH}_{4}\right)_{3}$ has gained prominent attention from the field of materials science ${ }^{16,48}$ and the transformation into more suitable hydrogen-storage materials as ammine aluminium borohydrides $^{49-51}$ and aluminoboranes ${ }^{52}$ is explored. Given this background, it is desirable to have access to a room temperature-stable and well-defined model complex such as $\left\{\mu \text {-LAl }\left(\mathrm{BH}_{4}\right)_{2}\right\}_{2}(4)$ in which the relevant aluminium centres and borohydride moieties are unified. 


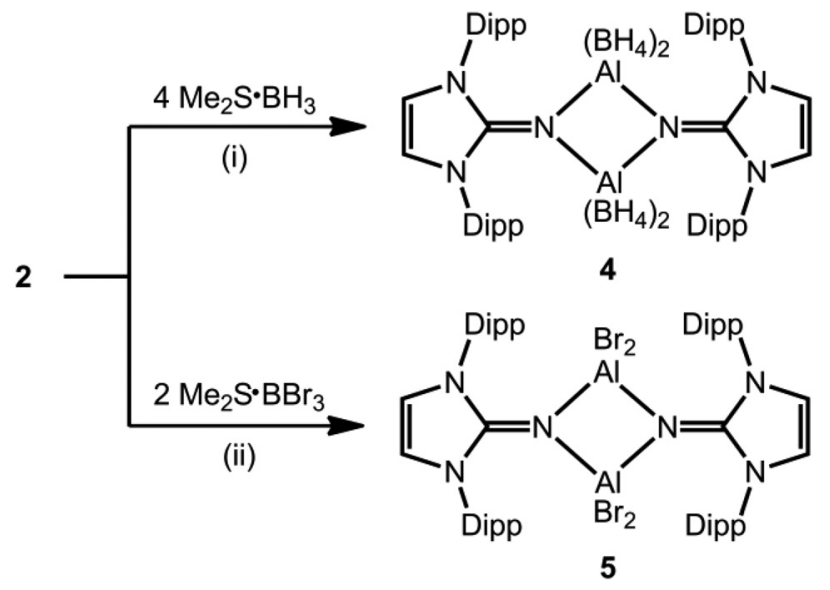

Scheme 2 Conversion of the aluminium dihydride 2 with the dimethylsulphide complexes of borane (top) or boron tribromide (bottom) yielding 4 and 5, respectively. (i) Toluene, (1) $-78{ }^{\circ} \mathrm{C}, 2 \mathrm{~h}$, (2) rt, $24 \mathrm{~h}$. (ii) Toluene, (1) $0^{\circ} \mathrm{C}, 20 \mathrm{~min}$, (2) $80^{\circ} \mathrm{C}, 3 \mathrm{~d}$. Dipp = 2,6-diisopropylphenyl.

In the infrared spectrum of $\mathbf{4}$ we assign absorptions at $2492 \mathrm{~cm}^{-1}$ and $2431 \mathrm{~cm}^{-1}$ to be produced by the $\mathrm{B}-\mathrm{H}$ bonds in 4. The symmetric and asymmetric $\mathrm{BH}$ stretches of $\mathrm{Al}\left(\mathrm{BH}_{4}\right)_{3}$ have been reported at a comparable wavenumber. ${ }^{53}$ In the ${ }^{1} \mathrm{H}$ and ${ }^{13} \mathrm{C}\left\{{ }^{1} \mathrm{H}\right\}$ NMR spectra of 4 (THF- $\left.\mathrm{d}_{8}\right)$, a deviation from the expected signal pattern for L ( $c f$. the NMR data of 2 ) is found in that the resonances of the Dipp moieties split into two signal sets of equal intensity. The 16 hydrogen atoms of the $\mathrm{BH}_{4}$ groups give rise to a broad resonance at $-0.33 \mathrm{ppm}$ in the ${ }^{1} \mathrm{H}$ NMR spectrum. The chemical shift of the boron nuclei amounts to $-37 \mathrm{ppm}\left(h_{1 / 2}=270 \mathrm{~Hz}\right)$ as observed in the ${ }^{11} \mathrm{~B}\left\{{ }^{1} \mathrm{H}\right\}$ NMR spectrum (THF- $\mathrm{d}_{8}$ ). In the proton-coupled ${ }^{11} \mathrm{~B}$ NMR spectrum, only a broad singlet at $-37 \mathrm{ppm}\left(h_{1 / 2}=380 \mathrm{~Hz}\right)$ is observed ( $c f$. (Dipp)nacnacAl $\left(\mathrm{BH}_{4}\right)_{2}: \delta\left({ }^{11} \mathrm{~B}\right)=-36.6 \mathrm{ppm}$, quintet, $\left.J=85.3 \mathrm{~Hz}, \mathrm{C}_{6} \mathrm{D}_{6}\right) .{ }^{46}$ Obviously, the $J$ coupling between boron and hydrogen in $\mathbf{4}$ is not resolved. However, the signal broadening of $110 \mathrm{~Hz}$ in the proton-coupled ${ }^{11} \mathrm{~B}$ NMR spectrum suggests the presence of borohydride moieties. After storing a flame-sealed NMR tube with a sample of 4 in THF- $\mathrm{d}_{8}$ at room temperature for two weeks no signs of decomposition were observed. However, upon heating to $60^{\circ} \mathrm{C}$ overnight the NMR spectroscopic analysis revealed a new species giving rise to an additional imino ligand signal set in the ${ }^{1} \mathrm{H}$ NMR spectrum, as well as a second singlet in the ${ }^{11} \mathrm{~B}\left\{{ }^{1} \mathrm{H}\right\}$ NMR spectrum at $-21.5 \mathrm{ppm}$. After the sample tube had been exposed to a temperature of $90{ }^{\circ} \mathrm{C}$ for $2 \mathrm{~d}$ compound 4 had been consumed entirely and the proton NMR spectrum evidenced the formation of several unidentified products, as well as dihydrogen. Crystallization of $\mathbf{4}$ from toluene-THF-hexane yielded single crystals suitable for X-ray diffraction analysis which contained 1.5 equivalents of toluene in the lattice. The X-ray study confirms the dimeric formulation of compound 4 (Fig. 6) and the structural parameters of the $\mathrm{Al}_{2} \mathrm{~N}_{2}$ ring and of the attached iminato ligands resemble the geometry of the corresponding groups in 2. The Al-N bond lengths in 4 lie in a range from 1.873(2) $\AA$ to $1.889(2) \AA$, which marks a slight decrease in

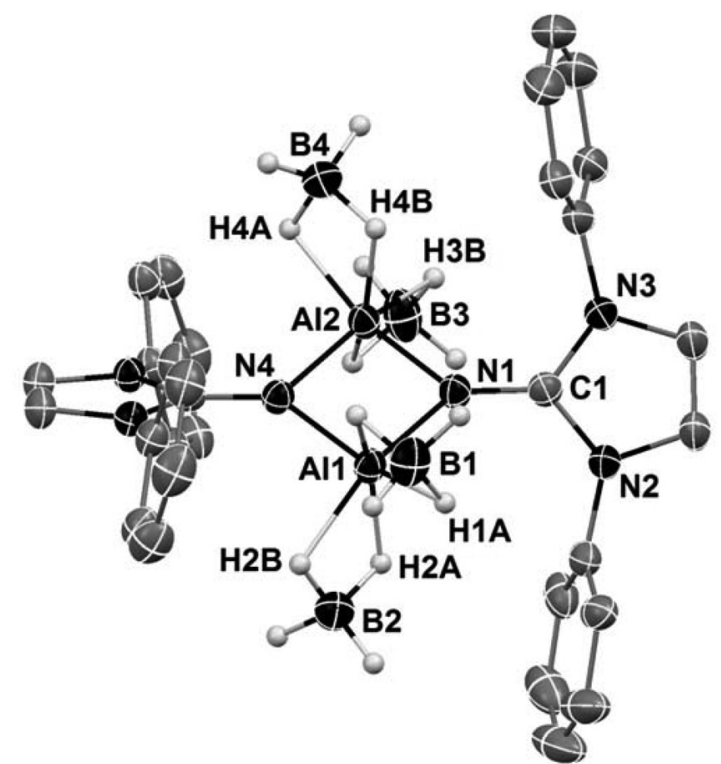

Fig. 6 Molecular structure of $\mathbf{4}$ (toluene) ${ }_{1.5}$ in the solid state. Hydrogen atoms (except on boron), isopropyl groups, and toluene molecules have been omitted for clarity; displacement ellipsoids are drawn at the 50\% probability level. Selected bond lengths $(\AA)$, atom $\cdots$ atom distances $(\AA)$, and bond angles ( ${ }^{\circ}$ : $\mathrm{Al}(1)-\mathrm{H}(2 \mathrm{~A}) 1.69(2), \mathrm{Al}(1)-\mathrm{H}(2 \mathrm{~B}) 1.82(2), \mathrm{Al}(2)-\mathrm{N}(1)$ 1.873(2), $\mathrm{Al}(2)-\mathrm{N}(4)$ 1.889(2), $\mathrm{N}(1)-\mathrm{C}(1)$ 1.319(2), $\mathrm{Al}(1) \cdots \mathrm{Al}(2)$ 2.728(1), $\mathrm{Al}(1) \cdots \mathrm{B}(1) \quad 2.229(3), \quad \mathrm{Al}(1) \cdots \mathrm{B}(2) \quad 2.220(3) ; \quad \mathrm{N}(1)-\mathrm{Al}(1)-\mathrm{N}(4) \quad 87.0(1)$, $\mathrm{N}(1)-\mathrm{Al}(2)-\mathrm{N}(4)$ 87.1(1), Al(1)-N(1)-Al(2) 93.2(1), Al(1)-N(4)-Al(2) 92.7(1), $\mathrm{Al}(1)-\mathrm{N}(1)-\mathrm{C}(1)$ 134.0(1).

comparison to the respective distances in $2(\mathrm{Al}-\mathrm{N}=1.912(1) \AA$ and 1.915(1) А; vide supra). The shorter Al-N bond lengths coincide with marginally more acute $\mathrm{Al}-\mathrm{N}-\mathrm{Al}^{\prime}$ bond angles $\left(92.7(1)^{\circ}\right.$ and $\left.93.2(1)^{\circ}\right)$ in 4 as compared to $93.8(1)^{\circ}$ in 2 . Accordingly, the $\mathrm{Al}(1) \cdots \mathrm{Al}(2)$ distance is shortened to $2.728(1)$ $\AA$ with respect to 2.795(1) A for the corresponding distance in 2. Concomitantly, the decrease in the Al-N distances leads to an increase in the exocyclic imino groups' bond lengths as exemplified by $\mathrm{N}(1)-\mathrm{C}(1)=1.319(2) \AA$ in 4 compared to $\mathrm{N}(1)-$ $\mathrm{C}(1)=1.289(2) \AA$ in 2 . When taking a look at how the Al-N bond lengths in II (Fig. 1) are affected by the transformation into Dipp(nacnac)Al $\left(\mathrm{BH}_{4}\right)_{2}$ one finds the $\mathrm{Al}-\mathrm{N}$ distance of 1.899(1) $\mathrm{A}$ in II $^{54}$ essentially unaltered upon conversion into its aluminium borohydride congener $(\mathrm{Al}-\mathrm{N}=1.898(3) \AA) .{ }^{46}$ In this case, the bidentate $\beta$-diketiminato ligand appears to be more rigid, allowing for less structural flexibility in its resulting aluminium complexes than the non-chelate-fashioned imino group in 2 and $\mathbf{4}$, respectively. The plane of the $\mathrm{Al}_{2} \mathrm{~N}_{2}$ ring in $\mathbf{4}$ intersects the planes of its adjacent imidazoline rings with dihedral angles of $34^{\circ}$ and $35^{\circ}$, respectively. This is notably more obscure than that in $2\left(9^{\circ}\right)$ and presumably due to the steric hindrance of the $\mathrm{BH}_{4}$ moieties in comparison to the hydrides in 2. With values between 1.07(3) $\AA$ and 1.19(2) A the similarity of all B-H bond lengths as a strong indicator for the formation of $\mathrm{BH}_{4}$ groups underlines the hydride transfer from the aluminium to the boron centre. Each aluminium atom can be described as coordinated by two $\mathrm{BH}_{4}{ }^{-}$groups in an $\eta^{2}$ fashion, 
which is marked by the eight $\mathrm{Al}-\mathrm{H}$ distances (1.69(2)-1.82(2) $\AA$ ). Considering that the coordination number of each aluminium atom is increased, it is a notable observation that the Al-N distances are only slightly affected (vide supra). The smallest $\mathrm{Al} \cdots \mathrm{B}$ distance in 4 amounts to 2.220(3) $\AA$ and the largest is determined to be $2.229(3) \AA$. This is in good agreement with the respective values in (Dipp)nacnacAl $\left(\mathrm{BH}_{4}\right)_{2}$ for which an $\eta^{2}$ coordination mode of the $\mathrm{BH}_{4}$ moieties to the aluminium atom has also been described. ${ }^{46}$ Accordingly, this type of bonding is also found for $\left\{\mu-\mathrm{Me}_{3} \operatorname{SiOAl}\left(\mathrm{BH}_{4}\right)_{2}\right\}_{2}(\mathrm{Al} \cdots \mathrm{B}=2.156(5) \AA$, 2.143(4) $\AA),{ }^{55}$ the parent $\mathrm{Al}\left(\mathrm{BH}_{4}\right)_{3}(\mathrm{Al} \cdots \mathrm{B}=2.143(3) \AA),{ }^{56}$ and related aluminium borohydrides. ${ }^{57,58}$

\section{Hydride-halide exchange between aluminium and boron}

The hydride transfer from $\left\{\mu \text { - } \mathrm{LAlH}_{2}\right\}_{2}$ (2) to $\mathrm{Me}_{2} \mathrm{~S} \cdot \mathrm{BH}_{3}$ yielding $\left\{\mu \text {-LAl }\left(\mathrm{BH}_{4}\right)_{2}\right\}_{2}(4)$ prompted us to investigate the reactivity of 2 towards other boron-centred electrophiles. A hydride-halide exchange reaction between a Lewis base complex of a boron trihalide and 2 might equilibrate a haloalane product due to the comparably high stability of many hydridoborane adducts. ${ }^{59,60}$ One would expect the degree of hydrogenation at the boron atom to reflect the halogenation of the aluminium centre which would allow monitoring of the reaction progress by proton-coupled ${ }^{11} \mathrm{~B}$ NMR spectroscopy. We chose the boron tribromide dimethylsulphide complex ${ }^{61,62}$ as a suitable bromide-transfer reagent because it can be conveniently stored and handled as a solid under an inert atmosphere, yet, it readily undergoes bromide-hydride exchange reactions in solution. ${ }^{62}$ First, we examined the conversion of 2 with two equivalents of $\mathrm{Me}_{2} \mathrm{~S} \cdot \mathrm{BBr}_{3}$ in $\mathrm{C}_{6} \mathrm{D}_{6}$ by preparing an experiment in the NMR tube. It turned out that an initial reaction took place at room temperature as marked in the ${ }^{11} \mathrm{~B}$ NMR spectrum by a doublet at $-7.8 \mathrm{ppm}(J=160 \mathrm{~Hz}$, assigned to $\left.\mathrm{Me}_{2} \mathrm{~S} \cdot \mathrm{BHBr}_{2}\right)^{62}$ and a triplet of weaker intensity at $-10.8 \mathrm{ppm}$ $\left(J=130 \mathrm{~Hz} \text {, assigned to } \mathrm{Me}_{2} \mathrm{~S} \cdot \mathrm{BH}_{2} \mathrm{Br}\right)^{62}$ that superimposed with the resonance caused by the residual starting material $\left(\mathrm{Me}_{2} \mathrm{~S} \cdot \mathrm{BBr}_{3}: \delta\left({ }^{11} \mathrm{~B}\right)\right.$ was observed at $-10.7 \mathrm{ppm}$ in $\left.\mathrm{C}_{6} \mathrm{D}_{6}\right)$. We stored the flame-sealed NMR tube at elevated temperature until the ${ }^{1} \mathrm{H}$ and ${ }^{11} \mathrm{~B}$ NMR spectra indicated the conversion to be complete. Accordingly, the reaction on a preparative scale in toluene granted the analytically pure aluminium dibromide $\{\mu \text {-LAlBr }\}_{2}$ (5) in $57 \%$ yield (Scheme 2). The formulation as a dimeric compound is evidenced by the high resolution mass spectrometric analysis, as well as single-crystal X-ray study (Fig. 7).

The ${ }^{1} \mathrm{H}$ and ${ }^{13} \mathrm{C}\left\{{ }^{1} \mathrm{H}\right\}$ NMR spectra $\left(\mathrm{C}_{6} \mathrm{D}_{6}\right)$ of 5 differ only insignificantly with respect to 2 , taking aside the expected disappearance of the broad resonance at $2.60 \mathrm{ppm}$ caused by the hydrogen atoms of the $\mathrm{AlH}_{2}$ moieties in 2. The single-crystal diffraction analysis of 5 shows that, as in 4, 1.5 equivalents of toluene are incorporated into the crystal lattice. The structural parameters of the planar $\mathrm{Al}_{2} \mathrm{~N}_{2}$ ring and the adjacent imidazoline rings in $\mathbf{5}$ are very similar to $\mathbf{4}$. The Al-N bond lengths in $\mathbf{5}$ lie in a range from 1.858(3) $\AA$ to 1.871(3) $\AA$ and are slightly shorter in comparison to those in 4 . Though rather marginal with respect to $\mathbf{4}$ the difference from the analogous bond

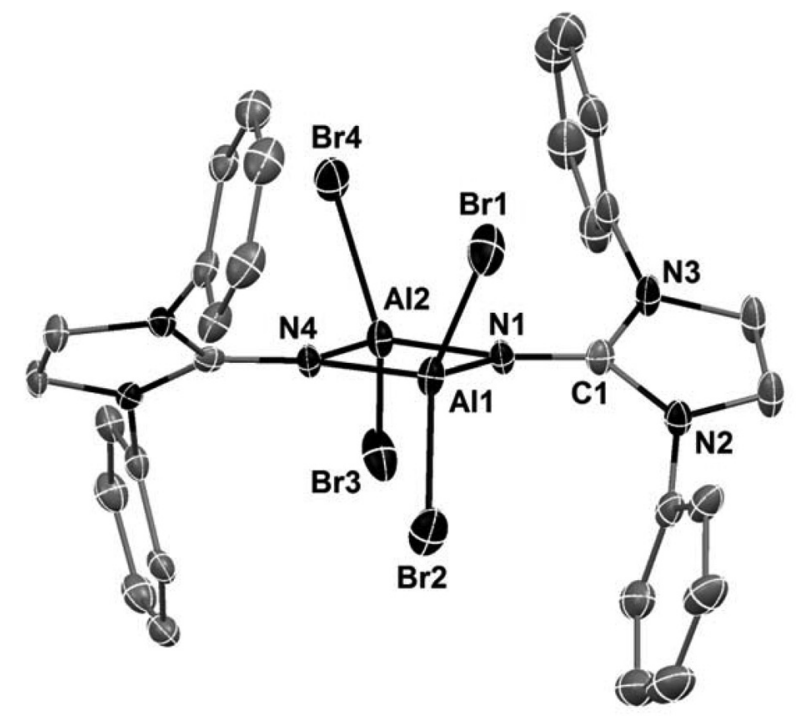

Fig. 7 Molecular structure of 5 (toluene) ${ }_{1.5}$ in the solid state. Hydrogen atoms, isopropyl groups, and toluene molecules have been omitted for clarity; displacement ellipsoids are drawn at the $50 \%$ probability level. Selected bond lengths ( $(\AA)$, atom $\cdots$ atom distance $(\AA)$, and bond angles $\left({ }^{\circ}\right)$ : $\operatorname{Br}(2)-\mathrm{Al}(1) 2.282(1), \operatorname{Br}(4)-\mathrm{Al}(2) 2.298(1), \operatorname{Al}(1)-\mathrm{N}(4)$ 1.871(3), $\mathrm{Al}(2)-\mathrm{N}(1)$ 1.858(3), N(1)-C(1) 1.318(4), $\mathrm{Al}(1) \ldots \mathrm{Al}(2) 2.687(1) ; \mathrm{Br}(1)-\mathrm{Al}(1)-\mathrm{Br}(2)$ 110.29(4), N(1)-Al(1)-N(4) 87.7(1), N(1)-Al(2)-N(4) 88.1(1), Al(1)-N(1)-Al(2) 92.3(1), $\mathrm{Al}(1)-\mathrm{N}(4)-\mathrm{Al}(2)$ 91.9(1), $\mathrm{Al}(1)-\mathrm{N}(1)-\mathrm{C}(1) 134.0(2)$.

lengths in $2(\mathrm{Al}-\mathrm{N}=1.912(1) \AA, 1.915(1) \AA)$ is now marked and one would assume that it correlates to the stronger electronwithdrawing nature of the bromide substituents in $\mathbf{5}$ as compared to the hydrides in 2 . In consequence, the electrophilicity of the aluminium centres is increased and the interaction with the nitrogen atoms of the imino ligands is strengthened. In accordance with the observed trend in the bond lengths comparing $\mathbf{2}, \mathbf{4}$, and $\mathbf{5}$, the $\mathrm{N}-\mathrm{Al}-\mathrm{N}^{\prime}$ bond angles in $\mathbf{5}$ have yet again slightly sharpened to $91.9(1)^{\circ}$ and $92.3(1)^{\circ}$, respectively. The interesting consequence of the aforementioned marginal changes in the geometry of the $\mathrm{Al}_{2} \mathrm{~N}_{2}$ core is revealed if one notes the $\mathrm{Al}(1) \cdots \mathrm{Al}(2)$ distance in 5 to amount to 2.687(1) A. This value is close to the range of metal-metal bond lengths in prominent dialanes with four-coordinated metal centres. ${ }^{19,43}$ However, we would not suggest that a bonding interaction between the $\mathrm{Al}$ atoms in $\mathbf{5}$ exists.

Motivated by the prospective results of the conversion of 2 with $\mathrm{Me}_{2} \mathrm{~S} \cdot \mathrm{BBr}_{3}$ we decided to explore the general applicability of the hydride-halide exchange concept. The conversion of 2 with two equivalents of boron trichloride yielded the aluminium dichloride $\{\mu \text {-LAlCl }\}_{2}$ (6) (Scheme 3, cf. the ESI $\dagger$ for experimental details). However, the ${ }^{1} \mathrm{H}$ NMR spectrum of the reaction mixture $\left(\mathrm{CDCl}_{3}\right)$ revealed signal sets induced by yet unassigned additional species of $\mathrm{L}$, presumably intermediate forms in the path of the reaction from 2 to 6 . This came as a surprise as we would have ascribed high reactivity to the uncomplexed form of $\mathrm{BCl}_{3}$. However, treating 2 with another two equivalents of this haloborane significantly improved the yield of $\mathbf{6}$. Alternatively, compound $\mathbf{6}$ was synthesized by 
2

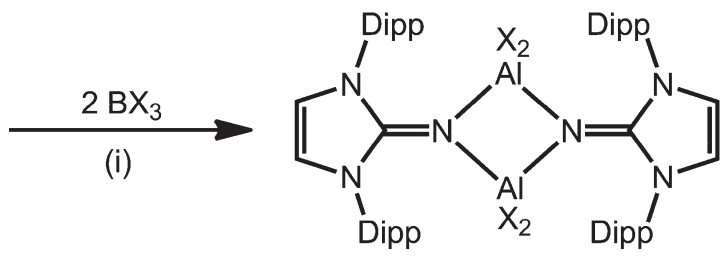

6: $\mathrm{X}=\mathrm{Cl}$

5: $\mathrm{X}=\mathrm{Br}$

7: $X=1$

Scheme 3 Syntheses of the imino aluminium dihalides 5, 6, and 7 via conversion of the aluminium dihydride 2 with boron trihalides. (i) Toluene, $-78^{\circ} \mathrm{C} \rightarrow \mathrm{rt}, 12 \mathrm{~h}$. Dipp $=2,6$-diisopropylphenyl.

reaction of bis(2,6-diisopropylphenyl)imidazolin-2-imino lithium ${ }^{34}$ $\{\mathrm{LLi}\}_{2}$ (8) with aluminium trichloride ( $c f$. the ESI for details on our synthesis of $\mathbf{8}$ and its molecular structure in the solid state, Fig. S3†). The formation of 6 was evidenced by high resolution mass spectrometry, NMR spectroscopy, as well as $\mathrm{X}$-ray crystallographic analysis. The essential structural characteristics of $\mathbf{6}$ strongly resemble the heavier halide congener $\mathbf{5}$ (cf. the ESI for the molecular structure of $\mathbf{6}$ in the solid state, Fig. S1 $\dagger$ ). Furthermore, parallels exist to the bulky phosphinimide $\left\{\mu-\left({ }^{\mathrm{t}} \mathrm{Bu}\right)_{3} \mathrm{PNAlCl}_{2}\right\}_{2}$ reported by Stephan and coworkers. ${ }^{23}$ Interestingly, 2,6-dimethylimidazolin-2-imino aluminium dichloride VII, a less sterically congested derivative of $\mathbf{6}$, forms a six-membered $\mathrm{Al}_{3} \mathrm{~N}_{3}$ ring in the solid state in which most Alcentred bond angles nearly fit the ideal value of a tetrahedron $\left(109.5^{\circ}\right) .{ }^{32}$ Thus, the square-planar geometry of the $\mathrm{Al}_{2} \mathrm{~N}_{2}$ core in 6 must result from the bulkiness of $\mathrm{L}$ in that it imposes smaller $\mathrm{Al}-\mathrm{N}-\mathrm{Al}^{\prime}$ angles than the iminato ligand in VII.

On the other hand, when we reacted 2 with two equivalents of $\mathrm{BBr}_{3}$, quantitative conversion to $\mathbf{5}$ was observed (NMR spectroscopic control, Scheme 3). Obviously, the reactivity of the heavier haloborane towards 2 is higher which is in line with the general trend in the Lewis acidity of boron trihalides that increases with rising atom number. ${ }^{63,64}$ It has to be pointed out that no elevated temperature is required for the reaction with boron tribromide to proceed which contrasts the conversion of 2 with $\mathrm{Me}_{2} \mathrm{~S} \cdot \mathrm{BBr}_{3}$ and, yet again, underlines the correlation between formation of the imino-substituted aluminium halide and the Lewis acidity of the haloborane employed.

To conclude our study on the hydride-halide exchange, we reacted 2 with two equivalents of boron triiodide (Scheme 3). It turned out that the reaction readily proceeded to give the aluminium diiodide $\left\{\mu-\mathrm{LAlI}_{2}\right\}_{2}$ (7) which we isolated in nearly quantitative yield (92\%). In accordance with our previous results, the high Lewis acidity of the boron triiodide promoted the reaction. ${ }^{63,64}$ Similar to its lower halide congeners 5 and $\mathbf{6}$, the single crystal X-ray data (Fig. S2, cf. the ESI $\dagger$ ) and the high resolution mass spectrum of 7 support its dimeric formulation. From a mixture of THF-hexane, compound 7 crystallizes with three equivalents of THF incorporated into the lattice. The ${ }^{1} \mathrm{H}$ NMR spectrum $\left(\mathrm{C}_{6} \mathrm{D}_{6}\right)$ of 7 shows the expected singlet for the four protons of the imidazoline ring of the imino ligands. Notably, in contrast to 2, 5, and 6 and similar to 4 splitting of the resonances induced by the Dipp moieties (Dipp $=2,6-{ }^{\mathrm{i}} \mathrm{Pr}_{2} \mathrm{C}_{6} \mathrm{H}_{3}$ ) into two signal sets of equal intensity occurs. In consequence, two doublets are observed for the hydrogen atoms in positions 3 and 5 of the $2,6-{ }^{\mathrm{i}} \mathrm{Pr}_{2} \mathrm{C}_{6} \mathrm{H}_{3}$ groups (7.27 ppm, $7.20 \mathrm{ppm}, J=8 \mathrm{~Hz}$ each) and two septets (3.61 ppm, $3.44 \mathrm{ppm}, J=7 \mathrm{~Hz}$ each), as well as two doublets of doublets result. Very likely, the splitting in 7 results from hindered rotation of the Dipp moieties due to the comparably large atom radius of iodine. As for $\mathbf{4}$, the characteristic deviation of the ${ }^{1} \mathrm{H}$ and ${ }^{13} \mathrm{C}\left\{{ }^{1} \mathrm{H}\right\}$ NMR spectra of 7 (vide supra) is not reflected in its molecular structure in the solid state and, accordingly, strong similarities exist to the lower halide congeners 5 and $\mathbf{6}$.

Precedence for the transformation of $\mathrm{Al}-\mathrm{H}$ groups into $\mathrm{Al}-\mathrm{X}$ functionalities (with $\mathrm{X}=\mathrm{Cl}, \mathrm{Br}$ or $\mathrm{I}$ ) using $\mathrm{BX}_{3}$ or Lewis base adducts thereof is scarcely found in the literature. To the best of our knowledge, the only related examples refer to the halogenation of $\mathrm{Al}-\mathrm{H}$ moieties in carbaalane clusters employing the higher haloboranes. ${ }^{65,66}$ Obviously, the direct conversion of an aluminium hydride complex with $\mathrm{X}_{2}$ offers an alternative methodology for halogenation at the metal centre. For this procedure we found few reports in the literature merely reporting on respective iodinations. ${ }^{19,67-69}$ These comprise only one example $^{68}$ in which an aluminium hydride bearing a monodentate $\mathrm{N}$-donor ligand is subject to conversion with $\mathrm{I}_{2}$ and, thus, is strongly related to our report of a non-chelatefashioned iminato system. Notably, a mixture of products is obtained in this report and we interpret this in terms of an endorsement of our halogenation approach with $\mathrm{BX}_{3}$ as an alternative option to $\mathrm{X}_{2}$. Furthermore, it should be pointed out that our conversions of imidazolin-2-iminato lithium $\{\mathrm{LLi}\}_{2}(8)$ with $\mathrm{AlBr}_{3}$ or $\mathrm{AlI}_{3}$ did not result in the formation of 5 and 7, respectively. Hence, our investigation of the hydride-halide exchange between aluminium and boron contributes to modern inorganic chemistry in that it may provide access to aluminium halide complexes where standard halogenation and salt metathesis protocols fail.

\section{Conclusions}

We have described the synthesis of the dimeric bis(2,6-diisopropylphenyl)imidazolin-2-imino aluminium dihydride $\left\{\mu-\mathrm{LAlH}_{2}\right\}_{2}$ (2). The strong electron-donating properties of the iminato ligand result in the ability of 2 to act as a potent hydride-transfer reagent. This was demonstrated by the synthesis of $\{\mu-\mathrm{LAl}(\mathrm{H}) \mathrm{OTf}\}_{2}(3),\left\{\mu-\mathrm{LAl}\left(\mathrm{BH}_{4}\right)_{2}\right\}_{2}(4),\left\{\mu-\mathrm{LAlBr}_{2}\right\}_{2}(5)$, $\left\{\mu-\mathrm{LAlCl}_{2}\right\}_{2}(6)$, and $\left\{\mu-\mathrm{LAlI}_{2}\right\}_{2}$ (7) via conversion of 2 with several Lewis acids (i.e. $\mathrm{Me}_{3} \mathrm{SiOTf}, \mathrm{Me}_{2} \mathrm{~S} \cdot \mathrm{BH}_{3}, \mathrm{Me}_{2} \mathrm{~S} \cdot \mathrm{BBr}_{3}, \mathrm{BCl}_{3}$, $\mathrm{BBr}_{3}$, and $\mathrm{BI}_{3}$ ). All new imidazolin-2-iminato aluminium compounds reported in this paper form dimers with a prominent square-planar $\mathrm{Al}_{2} \mathrm{~N}_{2}$ structural motif and the essential characteristics of the molecular structure in the solid state stay largely untouched when replacing the hydride substituents for halides or tetrahydridoborates. 
Importantly, aluminium dihydride 2 possesses potential for applications such as hydroalumination and activation of unpolarized element-element bonds (e.g. S-S, Se-Se bonds), as well as in the field of hydrogen-storage materials. We are currently exploring the reactivity of 2 in this regard. In addition, we will target cationic, as well as low-valent aluminium compounds by applying halide abstraction- and reductive dehalogenation protocols, respectively, using 5, 6, and 7 .

\section{Experimental}

\section{General considerations}

All experiments and manipulations were carried out under dry oxygen-free nitrogen using standard Schlenk techniques or in an MBraun drybox containing an atmosphere of purified nitrogen. Glass junctions were coated with the PTFE-based grease Merkel Triboflon III. Solvents were dried by standard methods and freshly distilled prior to use. NMR spectra were recorded on Bruker Avance II 200 or Avance III 500 spectrometers. Chemical shift values are referenced to (residual) solvent signals $\left({ }^{1} \mathrm{H}\right.$ and $\left.{ }^{13} \mathrm{C}\left\{{ }^{1} \mathrm{H}\right\} \mathrm{NMR}\right){ }^{70}$ to external $\mathrm{Et}_{2} \mathrm{O} \cdot \mathrm{BF}_{3}\left({ }^{11} \mathrm{~B}\right.$ and ${ }^{11} \mathrm{~B}\left\{{ }^{1} \mathrm{H}\right\}$ NMR) or to external $\mathrm{CFCl}_{3}\left({ }^{19} \mathrm{~F}\right.$ NMR). $J$ coupling values are reported in Hz. Abbreviations: $\mathrm{s}=$ singlet, $\mathrm{d}=$ doublet, $\mathrm{t}=$ triplet, sept $=$ septet, $\mathrm{br}=$ broad, n.o. $=$ not observed, n.r. = not resolved, Dipp = 2,6-diisopropylphenyl, L = bis(2,6-diisopropylphenyl)imidazolin-2-imino. High resolution mass spectra were recorded on a Thermo Fisher Scientific LTQ Orbitrap XL using an APCI ion source and providing the analyte dissolved in toluene, $\mathrm{C}_{6} \mathrm{D}_{6}$, or THF. Elemental analyses were performed by the microanalytical laboratory of the Institut für Chemie, Technische Universität Berlin. Reagents purchased from commercial sources were used as received if not stated otherwise. Boron tribromide was stored over mercury. Boron triiodide (95\% grade) was supplied by Sigma-Aldrich Corporation. Borane dimethylsulphide complex (5-6\% excess dimethylsulphide) was purchased from abcr GmbH \& Co. KG. $\mathrm{LH},{ }^{38} \mathrm{Me}_{3} \mathrm{~N} \cdot \mathrm{AlH}_{3}{ }^{71}$ and $\mathrm{Me}_{2} \mathrm{~S} \cdot \mathrm{BBr}_{3}{ }^{61}$ were synthesized according to the reported procedures. $C f$. the ESI $\dagger$ for the synthesis of $\{\mathrm{LLi}\}_{2}(\mathbf{8})$.

\section{Synthetic procedures}

Synthesis of $\left\{\boldsymbol{\mu}-\mathrm{L}\left(\mathrm{AlH}_{2}\right)\right\}_{2}$ (2). A solid mixture of $\mathrm{LH}$ $(1,5.12 \mathrm{~g}, 12.7 \mathrm{mmol})$ and $\mathrm{Me}_{3} \mathrm{~N} \cdot \mathrm{AlH}_{3}(1.13 \mathrm{~g}, 12.7 \mathrm{mmol})$ was cooled to $-78{ }^{\circ} \mathrm{C}$. Under stirring, toluene $(40 \mathrm{~mL})$ was added via a syringe and the reaction was allowed to proceed for $2 \mathrm{~h}$ with the cooling applied followed by a period of $24 \mathrm{~h}$ at room temperature (caution: gas evolution!). From the resulting solution the volatiles were evaporated under reduced pressure and the residue was recrystallized from a hot mixture of hexanetoluene $(60 \mathrm{~mL} / 10 \mathrm{~mL})$. After crystal formation had been completed at room temperature the supernatant was decanted and stored at low temperature $\left(4{ }^{\circ} \mathrm{C}\right.$ and $-30{ }^{\circ} \mathrm{C}$ consecutively) for $3 \mathrm{~d}$ yielding a second crop. By this method, single crystals suitable for X-ray diffraction analysis could be obtained. The crystal fractions were combined and dried in vacuo. Yield:
3.63 g, 66\% (Found: C, 75.11; H, 8.82; N, 9.67\%. Calc. for $\mathrm{C}_{54} \mathrm{H}_{76} \mathrm{Al}_{2} \mathrm{~N}_{6}$ [863.18]: C, 75.14; H, 8.87; N, 9.74\%). Decomp.: $>260{ }^{\circ} \mathrm{C}$.

IR: $\tilde{\nu} / \mathrm{cm}^{-1}=1830,1798(\mathrm{AlH}) .{ }^{1} \mathrm{H}$ NMR (500.1 MHz, $\left.\mathrm{C}_{6} \mathrm{D}_{6}\right)$ : $\delta=7.29(\mathrm{t}, J=8,4 \mathrm{H}, \mathrm{DippH}-4), 7.11$ (d, $J=8,8 \mathrm{H}, \mathrm{DippH}-3,5)$, 5.85 (s, $4 \mathrm{H}, \mathrm{NCH}$ ), 3.02 (sept, $\left.J=7,8 \mathrm{H}, \mathrm{CH}\left(\mathrm{CH}_{3}\right)_{2}\right), 2.60$ (br, $\left.4 \mathrm{H}, \mathrm{Al} H_{2}\right), 1.45$ (d, $\left.J=7,24 \mathrm{H}, \mathrm{CH}\left(\mathrm{CH}_{3}\right)_{2}\right), 1.12(\mathrm{~d}, J=7,24 \mathrm{H}$, $\left.\mathrm{CH}\left(\mathrm{CH}_{3}\right)_{2}\right) ;{ }^{13} \mathrm{C}\left\{{ }^{1} \mathrm{H}\right\}$ NMR $\left(125.8 \mathrm{MHz}, \mathrm{C}_{6} \mathrm{D}_{6}\right): \delta=149.9(\mathrm{NCN})$, 148.8 (DippC-1), 133.0 (DippC-2,6), 130.3 (DippC-4), 124.2 (DippC-3,5), $115.7(\mathrm{NCH}), 29.1\left(\mathrm{CH}\left(\mathrm{CH}_{3}\right)_{2}\right), 25.5\left(\mathrm{CH}\left(\mathrm{CH}_{3}\right)_{2}\right)$, $22.6\left(\mathrm{CH}\left(\mathrm{CH}_{3}\right)_{2}\right)$.

HRMS: $m / z$ found (calc.): $895.5728[\mathrm{M}+\mathrm{H}+2 \mathrm{O}]^{+}(100 \%)$, (895.5733); 861.5676 [M - H $]^{+}$(33), (861.5679); 877.5627 $[\mathrm{M}+\mathrm{O}]^{+}(27),(877.5628)$.

Synthesis of $\{\boldsymbol{\mu} \text {-LAl(H)OTf }\}_{2} \quad$ (3). Under ice-cooling, $\mathrm{Me}_{3} \operatorname{SiOTf}(3.07 \mathrm{~g}, 2.50 \mathrm{~mL}, 13.8 \mathrm{mmol}$ ) was gradually added via a syringe to a stirred solution of $2(3.63 \mathrm{~g}, 4.2 \mathrm{mmol})$ in toluene $(20 \mathrm{~mL})$. After $30 \mathrm{~min}$, the ice-bath was removed and the reaction continued at room temperature for $24 \mathrm{~h}$. The volatiles were removed under reduced pressure, the residue washed with hexane $(30 \mathrm{~mL})$ and subjected to recrystallization from hexane-THF $(70 \mathrm{~mL} / 70 \mathrm{~mL})$. The solid material that formed at $-30{ }^{\circ} \mathrm{C}$ was isolated and dried in vacuo yielding $1.96 \mathrm{~g}$ of the product with sufficient purity for further conversions (NMR spectroscopic control). In order to obtain analytically pure 3 the crude product was dissolved in hexane-THF $(15 \mathrm{~mL} / 35 \mathrm{~mL})$ and a slight amount of insoluble material was removed from the resulting solution by filtration through a frit. The crystallization commenced after storage at $4{ }^{\circ} \mathrm{C}$ for $1 \mathrm{~d}$ and was allowed to complete at $-30{ }^{\circ} \mathrm{C}$ over a period of $3 \mathrm{~d}$. A solid fraction produced by this method provided X-ray quality single crystals. The crystalline material was separated from the mother liquor and dried in vacuo. Yield: $1.05 \mathrm{~g}$, $22 \%$ (Found: C, 58.62; H, 6.52; N, 6.96; S, 5.23\%. Calc. for $\mathrm{C}_{56} \mathrm{H}_{74} \mathrm{Al}_{2} \mathrm{~F}_{6} \mathrm{~N}_{6} \mathrm{O}_{6} \mathrm{~S}_{2}$ [1159.31]: C, 58.02; H, 6.43; N, 7.25; S, 5.53\%). Decomp.: $235-245^{\circ} \mathrm{C}$.

${ }^{1} \mathrm{H}$ NMR (200.1 MHz, $\left.\mathrm{CD}_{3} \mathrm{CN}\right): \delta=7.46(\mathrm{t}, J=8,4 \mathrm{H}$, DippH-4), 7.24 (d, $J=8,8 \mathrm{H}$, DippH-3,5), 6.74 (s, $4 \mathrm{H}, \mathrm{NCH}$ ), 2.59 (n.r., $8 \mathrm{H}, \mathrm{CH}\left(\mathrm{CH}_{3}\right)_{2}$ ), 1.21 (n.r., $\left.24 \mathrm{H}, \mathrm{CH}\left(\mathrm{CH}_{3}\right)_{2}\right), 1.05$ (d, $\left.J=7,24 \mathrm{H}, \mathrm{CH}\left(\mathrm{CH}_{3}\right)_{2}\right)$, n.o. $(\mathrm{Al} H) ;{ }^{13} \mathrm{C}\left\{{ }^{1} \mathrm{H}\right\}$ NMR $(50.3 \mathrm{MHz}$, $\mathrm{CD}_{3} \mathrm{CN}$ ): $\delta=152.5$ (NCN), 148.6 (DippC-1), 132.6 (DippC-2,6), 132.5 (DippC-4), 126.0 (DippC-3,5), $119.4(\mathrm{NCH}), 29.7\left(\mathrm{CH}\left(\mathrm{CH}_{3}\right)_{2}\right)$, $25.7\left(\mathrm{CH}\left(\mathrm{CH}_{3}\right)_{2}\right), 22.8$ (br, $\left.\mathrm{CH}\left(\mathrm{CH}_{3}\right)_{2}\right)$, n.o. $\left(\mathrm{CF}_{3}\right) ;{ }^{19} \mathrm{~F}$ NMR (188.3 MHz, $\left.\mathrm{CD}_{3} \mathrm{CN}\right): \delta=-78.3,-79.3\left(\mathrm{CF}_{3}\right)$.

HRMS: $m / z$ found (calc.): $1009.5107[\mathrm{M}-\mathrm{C}-3 \mathrm{~F}-3 \mathrm{O}-\mathrm{S}]^{+}$ (100\%), (1009.5126); 1157.4551 [M $-\mathrm{H}]^{+}$(8), (1157.4568); 1159.4712 [M+ H $]^{+}(5),(1159.4724)$.

Synthesis of $\left\{\boldsymbol{\mu}-\mathrm{L}\left(\mathrm{Al}\left(\mathrm{BH}_{4}\right)_{2}\right)\right\}_{2} \quad$ (4). In a Schlenk tube equipped with a PTFE-coated magnetic stirrer bar and a rubber septum 2 ( $0.366 \mathrm{~g}, 0.42 \mathrm{mmol}$ ) was dissolved in toluene $(5 \mathrm{~mL})$ and the resulting mixture was cooled to $-78^{\circ} \mathrm{C}$. Under stirring, a freshly prepared solution $\left(\begin{array}{ll}0.5 & \mathrm{M}\end{array}\right)$ of borane dimethylsulphide complex in toluene $(3.5 \mathrm{~mL}, 1.8 \mathrm{mmol})$ was added dropwise via a syringe over a period of $5 \mathrm{~min}$. The reaction mixture was slowly warmed to room temperature overnight. A colourless suspension formed that was stirred for an 
additional $6 \mathrm{~h}$, after which the precipitation was completed by gradual addition of hexane $(9 \mathrm{~mL})$. The septum was replaced by a glass stopper, and the solid was allowed to sediment overnight. Via a syringe, the supernatant was withdrawn $(16 \mathrm{~mL})$ and the residual solvent was evaporated under reduced pressure. The remaining colourless powder was dried in vacuo ( $3 \mathrm{~h}, 9 \times 10^{-2} \mathrm{mbar}$ ), and stored under nitrogen for $2 \mathrm{~d}$ before a sample was subjected to elemental analysis. Yield: $0.27 \mathrm{~g}$, $67 \%$ (Found: $\mathrm{C}, 71.43 ; \mathrm{H}, \quad 9.40 ; \mathrm{N}, 8.94 \%$. Calc. for $\mathrm{C}_{54} \mathrm{H}_{88} \mathrm{Al}_{2} \mathrm{~B}_{4} \mathrm{~N}_{6}$ [918.52] $\times 0.5 \mathrm{C}_{7} \mathrm{H}_{8}$ [92.14]: C, 71.60; H, 9.61; $\mathrm{N}, 8.71 \%)$. Decomp.: $>260{ }^{\circ} \mathrm{C}$.

IR: $\tilde{\nu} / \mathrm{cm}^{-1}=2492,2431(\mathrm{BH}) .{ }^{1} \mathrm{H}$ NMR $(500.1 \mathrm{MHz}$, THF- $\left._{8}\right): \delta=7.33(\mathrm{t}, J=8,4 \mathrm{H}$, DippH-4) $7.20(\mathrm{~d}, J=8,4 \mathrm{H}$, DippH-3,5), 7.16 (d, $J=8,4$ H, DippH-3,5), 6.58 (s, 4 H, NCH), 3.18 (sept, $\left.J=7,4 \mathrm{H}, \mathrm{CH}\left(\mathrm{CH}_{3}\right)_{2}\right), 2.97$ (sept, $J=7,4 \mathrm{H}$, $\left.\mathrm{CH}\left(\mathrm{CH}_{3}\right)_{2}\right), 1.29\left(\mathrm{~d}, J=7,12 \mathrm{H}, \mathrm{CH}\left(\mathrm{CH}_{3}\right)_{2}\right), 1.23(\mathrm{~d}, J=7,12 \mathrm{H}$, $\left.\mathrm{CH}\left(\mathrm{CH}_{3}\right)_{2}\right), 1.11\left(\mathrm{~d}, J=7,12 \mathrm{H}, \mathrm{CH}\left(\mathrm{CH}_{3}\right)_{2}\right), 0.89(\mathrm{~d}, J=7,12 \mathrm{H}$, $\left.\mathrm{CH}\left(\mathrm{CH}_{3}\right)_{2}\right),-0.34\left(\mathrm{br}, h_{1 / 2}=170 \mathrm{~Hz}, 16 \mathrm{H}, \mathrm{BH}\right) ;{ }^{13} \mathrm{C}\left\{{ }^{1} \mathrm{H}\right\} \mathrm{NMR}$ (125.8 MHz, THF-d $\left.\mathrm{d}_{8}\right): \delta=151.5(\mathrm{NCN}), 148.2(\operatorname{ArC}), 147.6(\operatorname{ArC})$, 135.0 (ArC), $131.4(\mathrm{ArC}), 125.8(\mathrm{ArC}), 124.8(\mathrm{ArC}), 119.9(\mathrm{NCH})$, $29.4\left(\mathrm{CH}\left(\mathrm{CH}_{3}\right)_{2}\right), \quad 28.8\left(\mathrm{CH}\left(\mathrm{CH}_{3}\right)_{2}\right), 27.2\left(\mathrm{CH}\left(\mathrm{CH}_{3}\right)_{2}\right), \quad 24.4$ $\left(\mathrm{CH}\left(\mathrm{CH}_{3}\right)_{2}\right), \quad 23.7 \quad\left(\mathrm{CH}\left(\mathrm{CH}_{3}\right)_{2}\right), 23.4 \quad\left(\mathrm{CH}\left(\mathrm{CH}_{3}\right)_{2}\right) ;{ }^{11} \mathrm{~B} \quad \mathrm{NMR}$ (64.2 MHz, THF-d $\left.\mathrm{d}_{8}\right): \delta=-37$ (n.r., $h_{1 / 2}=380 \mathrm{~Hz}$ ); ${ }^{11} \mathrm{~B}\left\{{ }^{1} \mathrm{H}\right\} \mathrm{NMR}$ $(64.2 \mathrm{MHz}$, THF-d 8$): \delta=-37\left(h_{1 / 2}=270 \mathrm{~Hz}\right)$.

HRMS: $m / z$ found (calc.): $875.6002[\mathrm{M}-10 \mathrm{H}-3 \mathrm{~B}]^{+}(11 \%)$, (875.6012).

Synthesis of $\left\{\boldsymbol{\mu}-\mathrm{LAlBr}_{2}\right\}_{2}$ (5). A Schlenk tube equipped with a PTFE-coated magnetic stirrer bar and a glass stopper was charged with $2(0.223 \mathrm{~g}, 0.26 \mathrm{mmol})$ and $\mathrm{Me}_{2} \mathrm{~S} \cdot \mathrm{BBr}_{3}(0.175 \mathrm{~g}$, $0.56 \mathrm{mmol}$ ) in the dry box. Under Schlenk conditions, the solid mixture was cooled to $0{ }^{\circ} \mathrm{C}$ and, with stirring, toluene $(4.5 \mathrm{~mL})$ was gradually added via a syringe. Stirring was continued at $0{ }^{\circ} \mathrm{C}$ for $20 \mathrm{~min}$ followed by replacement of the cooling for an oil-bath which was heated to $80^{\circ} \mathrm{C}$. After a short induction period, the Schlenk vessel was isolated from the inert-gas system by closing the tap and the reaction proceeded at this temperature for $3 \mathrm{~d}$. Using a frit, the warm reaction mixture was filtered in order to separate a slight amount of insoluble material. From the filtrate, crystals formed upon standing at room temperature overnight. In order to complete the crystallization process it was stored at $4{ }^{\circ} \mathrm{C}$ and at $-30{ }^{\circ} \mathrm{C}$ for a period of $24 \mathrm{~h}$ each time. By this method, crystals suitable for X-ray diffraction analysis were obtained. After decantation of the cold supernatant the solid residue was dried in vacuo for $3 \mathrm{~h}$ and stored for $1 \mathrm{~d}$ under nitrogen before it was subjected to elemental analysis. Yield: $0.19 \mathrm{~g}, 57 \%$ (Found: C, 58.05; $\mathrm{H}, 6.63 ; \mathrm{N}, 6.62 \%$. Calc. for $\mathrm{C}_{54} \mathrm{H}_{72} \mathrm{Al}_{2} \mathrm{Br}_{4} \mathrm{~N}_{6}[1178.77] \times \mathrm{C}_{7} \mathrm{H}_{8}$ [92.14]: C, 57.65; H, 6.34; N, 6.61\%).

${ }^{1} \mathrm{H}$ NMR $\left(500.1 \mathrm{MHz}, \mathrm{C}_{6} \mathrm{D}_{6}\right): \delta=7.31(\mathrm{t}, J=8,4 \mathrm{H}, \mathrm{DippH}-4)$, 7.22 (d, $J=8,8$ H, DippH-3,5), 5.84 (s, 4 H, NCH), 3.31 (sept, $\left.J=7,8 \mathrm{H}, \mathrm{CH}\left(\mathrm{CH}_{3}\right)_{2}\right), 1.57\left(\mathrm{~d}, J=7,24 \mathrm{H}, \mathrm{CH}\left(\mathrm{CH}_{3}\right)_{2}\right), 0.99$ (d, $\left.J=7,24 \mathrm{H}, \mathrm{CH}\left(\mathrm{CH}_{3}\right)_{2}\right) ;{ }^{13} \mathrm{C}\left\{{ }^{1} \mathrm{H}\right\}$ NMR (125.8 MHz, $\left.\mathrm{C}_{6} \mathrm{D}_{6}\right)$ : $\delta=151.5(\mathrm{NCN}), 147.6$ (DippC-1), 134.3 (DippC-2,6), 131.3 (DippC-4), 125.3 (DippC-3,5), $119.1(\mathrm{NCH}), 28.9\left(\mathrm{CH}\left(\mathrm{CH}_{3}\right)_{2}\right)$, $24.3\left(\mathrm{CH}\left(\mathrm{CH}_{3}\right)_{2}\right), 20.8\left(\mathrm{CH}\left(\mathrm{CH}_{3}\right)_{2}\right)$.

HRMS: $m / z$ found (calc.): $1178.2132[\mathrm{M}]^{+}(100 \%),(1178.2142)$.
Synthesis of $\left\{\boldsymbol{\mu}-\mathrm{LAlCl}_{2}\right\}_{2}$ (6). A stirring suspension of freshly sublimed $\mathrm{AlCl}_{3}(0.38 \mathrm{~g}, 2.8 \mathrm{mmol})$ in toluene $(8 \mathrm{~mL})$ was cooled to $0{ }^{\circ} \mathrm{C}$ and treated dropwise with a solution of $\{\mathrm{LLi}\}_{2}$ $(8,1.11 \mathrm{~g}, 1.4 \mathrm{mmol})$ in toluene $(19 \mathrm{~mL})$ over a period of $10 \mathrm{~min}$. The resulting reaction mixture was stirred at $0{ }^{\circ} \mathrm{C}$ for $30 \mathrm{~min}$, then the cooling was removed and the reaction continued for $12 \mathrm{~h}$ at room temperature. After filtration via a canula (glass fiber-coated inlet) the solvent was evaporated from the pale yellow solution under reduced pressure, the residue was washed with hexane (two portions of $15 \mathrm{~mL}$, removed $13 \mathrm{~mL}$ of supernatant each time), and the crude product was dried in vacuo. Yield: $0.74 \mathrm{~g}, 54 \%$ (cf. the ESI $†$ for depiction of the NMR spectra of the crude product in $\mathrm{CDCl}_{3}$ ). Single crystals suitable for X-ray diffraction analysis were obtained after dilution of the filtered reaction mixture with hexane $(10 \mathrm{~mL})$ and storage at $4{ }^{\circ} \mathrm{C}$ for $1 \mathrm{~d}$.

${ }^{1} \mathrm{H}$ NMR (500.1 MHz, $\left.\mathrm{C}_{6} \mathrm{D}_{6}\right): \delta=7.30(\mathrm{t}, J=8,4 \mathrm{H}, \mathrm{DippH}-4)$, 7.22 (d, $J=8,8$ H, DippH-3,5), 5.87 (s, 4 H, NCH), 3.17 (sept, $\left.J=7,8 \mathrm{H}, \mathrm{CH}\left(\mathrm{CH}_{3}\right)_{2}\right), 1.54\left(\mathrm{~d}, J=7,24 \mathrm{H}, \mathrm{CH}\left(\mathrm{CH}_{3}\right)_{2}\right), 1.00(\mathrm{~d}$, $\left.J=7,24 \mathrm{H}, \mathrm{CH}\left(\mathrm{CH}_{3}\right)_{2}\right) ;{ }^{13} \mathrm{C}\left\{{ }^{1} \mathrm{H}\right\}$ NMR (125.8 MHz, $\left.\mathrm{C}_{6} \mathrm{D}_{6}\right)$ : $\delta=151.8(\mathrm{NCN}), 147.6$ (DippC-1), 133.5 (DippC-2,6), 131.1 (DippC-4), 125.0 (DippC-3,5), $118.3(\mathrm{NCH}), 28.9\left(\mathrm{CH}\left(\mathrm{CH}_{3}\right)_{2}\right)$, $26.0\left(\mathrm{CH}\left(\mathrm{CH}_{3}\right)_{2}\right), 23.8\left(\mathrm{CH}\left(\mathrm{CH}_{3}\right)_{2}\right)$.

HRMS: $\mathrm{m} / \mathrm{z}$ found (calc.): $1001.4233[\mathrm{M}+\mathrm{H}]^{+}(28 \%)$, (1001.4252); $981.4605[\mathrm{M}-\mathrm{Cl}+2 \mathrm{H}+\mathrm{O}]^{+}$(26), (981.4620).

Synthesis of $\left\{\boldsymbol{\mu}-\mathrm{LAlI}_{2}\right\}_{2}(7)$. In the drybox, a solid mixture of $2(0.511 \mathrm{~g}, 0.59 \mathrm{mmol})$ and boron triiodide $(0.488 \mathrm{~g}$, $1.25 \mathrm{mmol}$ ) was prepared in a Schlenk vessel equipped with a PTFE-coated magnetic stirrer bar and a rubber septum. Under Schlenk conditions, it was cooled to $-78^{\circ} \mathrm{C}$ and, with stirring, toluene $(8 \mathrm{~mL})$ was gradually added via a syringe along the inner glass wall of the cold reaction vessel. The resulting reaction mixture was slowly allowed to warm to room temperature overnight. After $18 \mathrm{~h}$ the solvent was evaporated under reduced pressure and the colourless solid residue was dried in vacuo. It was redissolved in a mixture of hexane-THF $(6 \mathrm{~mL} / 12 \mathrm{~mL})$ and, using a frit, a slight amount of insoluble material was removed by filtration. The filtrate was stored at $4{ }^{\circ} \mathrm{C}$ for $24 \mathrm{~h}$. Separation of the crystalline product had commenced and was completed at $-30{ }^{\circ} \mathrm{C}$ for a period of $2 \mathrm{~d}$. The fraction, thus obtained, contained single crystals suitable for X-ray diffraction analysis. The cold supernatant was decanted and the solid was dried in vacuo. Yield: $0.74 \mathrm{~g}, 92 \%$ (Found: C, 47.81; H, 5.63; $\mathrm{N}, 5.87 \%$. Calc. for $\mathrm{C}_{54} \mathrm{H}_{72} \mathrm{Al}_{2} \mathrm{I}_{4} \mathrm{~N}_{6}$ [1366.77]: C, 47.45; H, 5.31; $\mathrm{N}, 6.15 \%)$.

${ }^{1} \mathrm{H}$ NMR (500.1 MHz, $\left.\mathrm{C}_{6} \mathrm{D}_{6}\right): \delta=7.32(\mathrm{t}, J=8,4 \mathrm{H}, \mathrm{DippH}-4)$, 7.27 (d, $J=8,4$ H, DippH-3,5), 7.20 (d, $J=8,4$ H, DippH-3,5), 5.76 (s, $4 \mathrm{H}, \mathrm{NCH}$ ), 3.61 (sept, $J=7,4 \mathrm{H}, \mathrm{CH}\left(\mathrm{CH}_{3}\right)_{2}$ ), 3.44 (sept, $\left.J=7,4 \mathrm{H}, \mathrm{CH}\left(\mathrm{CH}_{3}\right)_{2}\right), 1.63\left(\mathrm{~d}, J=7,12 \mathrm{H}, \mathrm{CH}\left(\mathrm{CH}_{3}\right)_{2}\right), 1.60(\mathrm{~d}$, $\left.J=7,12 \mathrm{H}, \mathrm{CH}\left(\mathrm{CH}_{3}\right)_{2}\right), 1.03\left(\mathrm{~d}, J=7,12 \mathrm{H}, \mathrm{CH}\left(\mathrm{CH}_{3}\right)_{2}\right), 0.93(\mathrm{~d}$, $\left.J=7,12 \mathrm{H}, \mathrm{CH}\left(\mathrm{CH}_{3}\right)_{2}\right) ;{ }^{13} \mathrm{C}\left\{{ }^{1} \mathrm{H}\right\}$ NMR (125.8 MHz, $\left.\mathrm{C}_{6} \mathrm{D}_{6}\right)$ : $\delta=151.2(\mathrm{NCN}), 147.6(\mathrm{ArC}), 147.4(\mathrm{ArC}), 136.0(\mathrm{ArC}), 131.6$ (ArC), $126.2(\mathrm{ArC}), 125.5(\mathrm{ArC}), 120.4(\mathrm{NCH}), 28.9\left(\mathrm{CH}\left(\mathrm{CH}_{3}\right)_{2}\right)$, $28.8\left(\mathrm{CH}\left(\mathrm{CH}_{3}\right)_{2}\right), 26.5\left(\mathrm{CH}\left(\mathrm{CH}_{3}\right)_{2}\right), 25.9\left(\mathrm{CH}\left(\mathrm{CH}_{3}\right)_{2}\right), \quad 24.4$ (n.r., $\left.2 \times \mathrm{CH}\left(\mathrm{CH}_{3}\right)_{2}\right)$. 
HRMS: $m / z$ found (calc.): $1239.2567[\mathrm{M}-\mathrm{I}]^{+}(100 \%)$, (1239.2583); $1257.2661[\mathrm{M}-\mathrm{I}+2 \mathrm{H}+\mathrm{O}]^{+}$(75), (1257.2689); 1367.1680 [M+ H $]^{+}(6),(1367.1706)$.

\section{Single crystal structure determination}

Data for the single-crystal structure determination of 2, 3, 4, and 7 were collected on an Agilent SuperNova diffractometer equipped with a CCD area Atlas detector and a mirror monochromator utilizing $\mathrm{CuK}_{\alpha}$ radiation $(\lambda=1.5418 \AA)$. Data for the single-crystal structure determination of $\mathbf{5}, \mathbf{6}$, and $\mathbf{8}$ were collected on an Oxford-Diffraction Xcalibur diffractometer equipped with a CCD area detector Sapphire $S$ and a graphite monochromator utilizing $\operatorname{MoK}_{\alpha}$ radiation $(\lambda=0.71073 \AA)$.

The crystal structures were solved by direct methods and refined on $F^{2}$ using full-matrix least squares with SHELXL-97. ${ }^{72}$ The positions of the $\mathrm{H}$ atoms of the carbon atoms were calculated and considered isotropically according to a riding model. The positions of the $\mathrm{H}$ atoms attached to the aluminium or the boron atoms at the compounds 2,3 , and 4 were found in the electron-density map and were refined without restraints of the interatomic distances.

\section{Acknowledgements}

We are exceptionally grateful to the Alexander von Humboldt foundation (Sofja Kovalevskaja Program) for financial support.

\section{Notes and references}

1 C. Jones, G. A. Koutsantonis and C. L. Raston, Polyhedron, 1993, 12, 1829.

2 C. L. Raston, A. F. H. Siu, C. J. Tranter and D. J. Young, Tetrahedron Lett., 1994, 35, 5915.

3 E.-i. Negishi, N. Okukado, A. O. King, D. E. Van Horn and B. I. Spiegel, J. Am. Chem. Soc., 1978, 100, 2254.

4 S. S. Kumar and H. W. Roesky, Dalton Trans., 2004, 3927.

5 E.-i. Negishi, G. Wang, H. Rao and Z. Xu, J. Org. Chem., 2010, 75, 3151.

6 E. Y. Pankratyev, T. V. Tyumkina, L. V. Parfenova, S. L. Khursan, L. M. Khalilov and U. M. Dzhemilev, Organometallics, 2011, 30, 6078.

7 P. Andrews, C. M. Latham, M. Magre, D. Willcox and S. Woodward, Chem. Commun., 2013, 49, 1488.

8 Y.-L. Lien, Y.-C. Chang, N.-T. Chuang, A. Datta, S.-J. Chen, C.-H. Hu, W.-Y. Huang, C.-H. Lin and J.-H. Huang, Inorg. Chem., 2010, 49, 136.

9 V. Jancik, Y. Peng, H. W. Roesky, J. Li, D. Neculai, A. M. Neculai and R. Herbst-Irmer, J. Am. Chem. Soc., 2003, $125,1452$.

10 C. Cui, H. W. Roesky, H. Hao, H.-G. Schmidt and M. Noltemeyer, Angew. Chem., Int. Ed., 2000, 39, 1815.

11 W. Uhl and B. Jana, Chem.-Eur. J., 2008, 14, 3067.

12 Y. Yang, H. Li, C. Wang and H. W. Roesky, Inorg. Chem., 2012, 51, 2204.
13 M. D. Francis, D. E. Hibbs, M. B. Hursthouse, C. Jones and N. A. Smithies, J. Chem. Soc., Dalton Trans., 1998, 3249.

14 R. J. Baker, M. L. Cole, C. Jones and M. F. Mahon, J. Chem. Soc., Dalton Trans., 2002, 1992.

15 S. Singh and H. W. Roesky, J. Fluorine Chem., 2007, 128, 369.

16 S.-i. Orimo, Y. Nakamori, J. R. Eliseo, A. Züttel and C. M. Jensen, Chem. Rev., 2007, 107, 4111.

17 R. Zidan, B. L. Garcia-Diaz, C. S. Fewox, A. C. Stowe, J. R. Gray and A. G. Harter, Chem. Commun., 2009, 3717.

18 C. Ganesamoorthy, S. Loerke, C. Gemel, P. Jerabek, M. Winter, G. Frenking and R. A. Fischer, Chem. Commun., 2013, 49, 2858.

19 S. J. Bonyhady, D. Collis, G. Frenking, N. Holzmann, C. Jones and A. Stasch, Nat. Chem., 2010, 2, 865.

20 I. M. Riddlestone, S. Edmonds, P. A. Kaufman, J. Urbano, J. I. Bates, M. J. Kelly, A. L. Thompson, R. Taylor and S. Aldrige, J. Am. Chem. Soc., 2012, 134, 2551.

21 J. A. B. Abdalla, I. M. Riddlestone, R. Tirfoin, N. Phillips, J. I. Bates and S. Aldridge, Chem. Commun., 2013, 49, 5547.

22 S. Courtenay, D. Walsh, S. Hawkeswood, P. Wei, A. K. Das and D. W. Stephan, Inorg. Chem., 2007, 46, 3623.

23 C. M. Ong, P. McKarns and D. W. Stephan, Organometallics, 1999, 18, 4197.

24 C. V. Cárdenas, M. Á. M. Hernández and J.-M. Grévy, Dalton Trans., 2010, 39, 6441.

25 H. V. R. Dias, W. Jin and R. E. Ratcliff, Inorg. Chem., 1995, 34, 6100.

26 T. R. Cundari, Chem. Rev., 2000, 100, 807.

27 J. M. Hopkins, M. Bowdridge, K. N. Robertson, T. S. Cameron, H. A. Jenkins and J. A. C. Clyburne, J. Org. Chem., 2001, 66, 5713.

28 M. Tamm, S. Randoll, E. Herdtweck, N. Kleigrewe, G. Kehr, G. Erker and B. Rieger, Dalton Trans., 2006, 459.

29 A. G. Trambitas, J. Yang, D. Melcher, C. G. Daniliuc, P. G. Jones, Z. Xie and M. Tamm, Organometallics, 2011, 30, 1122.

30 M. Sharma, H. S. Yameen, B. Tumanskii, S.-A. Filimon, M. Tamm and M. S. Eisen, J. Am. Chem. Soc., 2012, 134, 17234.

31 S. Inoue and K. Leszczyńska, Angew. Chem., Int. Ed., 2012, 51, 8589.

32 N. Kuhn, R. Fawzi, M. Steimann and J. Wiethoff, Z. Anorg. Allg. Chem., 1997, 623, 554.

33 N. Kuhn, U. Abram, C. Maichle-Mößmer and J. Wiethoff, Z. Anorg. Allg. Chem., 1997, 623, 1121.

34 S. Beer, K. Brandhorst, C. G. Hrib, X. Wu, B. Haberlag, J. Grunenberg, P. G. Jones and M. Tamm, Organometallics, 2009, 28, 1534.

35 R. Kinjo, B. Donnadieu and G. Bertrand, Angew. Chem., Int. Ed., 2010, 49, 5930.

36 F. Dielmann, O. Back, M. Henry-Ellinger, P. Jerabek, G. Frenking and G. Bertrand, Science, 2012, 337, 1526.

37 F. Dielmann, C. E. Moore, A. L. Rheingold and G. Bertrand, J. Am. Chem. Soc., 2013, 135, 14071. 
38 M. Tamm, D. Petrovic, S. Randoll, S. Beer, T. Bannenberg, P. G. Jones and J. Grunenberg, Org. Biomol. Chem., 2007, 5, 523.

39 N. Kuhn, S. Fuchs and M. Steimann, Z. Anorg. Allg. Chem., 2000, 626, 1387.

40 M. L. Cole, C. Jones, P. C. Junk, M. Kloth and A. Stasch, Chem.-Eur. J., 2005, 11, 4482.

41 C. Cui, H. W. Roesky, M. Noltemeyer and H.-G. Schmidt, Organometallics, 1999, 18, 5120.

42 A. J. Downs, D. Duckworth, J. C. Machell and C. R. Pulham, Polyhedron, 1992, 11, 1295.

43 I. L. Fedushkin, M. V. Moskalev, A. N. Lukoyanov, A. N. Tishkina, E. V. Baranov and G. A. Abakumov, Chem.-Eur. J., 2012, 18, 11264.

44 P. Dornan, C. N. Rowley, J. Priem, S. T. Barry, T. J. Burchell, T. K. Woo and D. S. Richeson, Chem. Commun., 2008, 3645.

45 G. Rayner-Canham, J. Chem. Educ., 2000, 77, 1053.

46 S. Harder and J. Spielmann, Chem. Commun., 2011, 47, 11945.

47 H. I. Schlesinger, H. C. Brown and E. K. Hyde, J. Am. Chem. Soc., 1953, 75, 209.

48 P. Zanella, L. Crociani, N. Masciocchi and G. Giunchi, Inorg. Chem., 2007, 46, 9039.

49 Y. Guo, X. Yu, W. Sun, D. Sun and W. Yang, Angew. Chem., Int. Ed., 2011, 50, 1087.

50 Y. Guo, H. Wu, W. Zhou and X. Yu, J. Am. Chem. Soc., 2011, 133, 4690.

51 Y. Guo, Y. Jiang, G. Xia and X. Yu, Chem. Commun., 2012, 48, 4408.

52 J.-C. Zhao, D. A. Knight, G. M. Brown, C. Kim, S.-J. Hwang, J. W. Reiter, R. C. Bowman Jr., J. A. Zan and J. G. Kulleck, J. Phys. Chem. C, 2009, 113, 2.

53 D. A. Coe and J. W. Nibler, Spectrochim. Acta, Part A, 1973, 29, 1789.

54 B. Twamley, N. J. Hardman and P. P. Power, Acta Crystallogr., Sect. E: Struct. Rep. Online, 2001, 57, m227.

55 P. Bissinger, P. Mikulcik, J. Riede, A. Schier and H. Schmidbaur, J. Organomet. Chem., 1993, 446, 37.
56 A. Almenningen, G. Gundersen and A. Haaland, Acta Chem. Scand., 1968, 22, 328.

57 S. Aldridge, A. J. Blake, A. J. Downs, R. O. Gould, S. Parsons and C. R. Pulham, J. Chem. Soc., Dalton Trans., 1997, 1007.

58 N. A. Bailey, P. H. Bird and M. G. H. Wallbridge, Inorg. Chem., 1968, 7, 1575.

59 T. D. Coyle, H. D. Kaesz and F. G. A. Stone, J. Am. Chem. Soc., 1959, 81, 2989.

60 L. M. Braun, R. A. Braun, H. R. Crissman, M. Opperman and R. M. Adams, J. Org. Chem., 1971, 36, 2388.

61 M. Schmidt and H. D. Block, Chem. Ber., 1970, 103, 3705.

62 H. C. Brown and N. Ravindran, Inorg. Chem., 1977, 16, 2938.

63 D. K. Straub, J. Chem. Educ., 1995, 72, 494.

64 D. J. Grant, D. A. Dixon, D. Camaioni, R. G. Potter and K. O. Christe, Inorg. Chem., 2009, 48, 8811.

65 A. Stasch, M. Ferbinteanu, J. Prust, W. Zheng, F. Cimpoesu, H. W. Roesky, J. Magull, H.-G. Schmidt and M. Noltemeyer, J. Am. Chem. Soc., 2002, 124, 5441.

66 A. Stasch, H. W. Roesky, D. Vidovic, J. Magull, H.-G. Schmidt and M. Noltemeyer, Inorg. Chem., 2004, 43, 3625 .

67 W. Zheng, H. W. Roesky, N. C. Mösch-Zanetti, H.-G. Schmidt and M. Noltemeyer, Eur. J. Inorg. Chem., 2002, 1056.

68 T. Bauer, S. Schulz and M. Nieger, Z. Anorg. Allg. Chem., 2004, 630, 1807.

69 C. Jones, P. C. Junk, M. Kloth, K. M. Proctor and A. Stasch, Polyhedron, 2006, 25, 1592.

70 G. R. Fulmer, A. J. M. Miller, N. H. Sherden, H. E. Gottlieb, A. Nudelman, B. M. Stoltz, J. E. Bercaw and K. I. Goldberg, Organometallics, 2010, 29, 2176.

71 J. K. Ruff and M. F. Hawthorne, J. Am. Chem. Soc., 1960, 82, 2141.

72 G. M. Sheldrick, SHELXL-97, Program for refinement of crystal structures, University of Göttingen, Germany, 1997. 